OPTOGENETIC STIMULATION OF LATERAL HYPOTHALAMIC OREXIN/DYNORPHIN INPUTS IN

THE VENTRAL TEGMENTAL AREA POTENTIATES MESOLIMBIC DOPAMINE

NEUROTRANSMISSION AND PROMOTES REWARD-SEEKING BEHAVIOURS

Catherine S. Thomas ${ }^{1}$, Aida Mohammadkhani ${ }^{1}$, Madiha Rana ${ }^{1}$, Min Qiao $^{1}$, Corey Baimel ${ }^{1}$,

Stephanie L. Borgland ${ }^{1,2}$

${ }^{1}$ Department of Physiology and Pharmacology

Hotchkiss Brain Institute

The University of Calgary

3330 Hospital Dr. NW

Calgary, Alberta T2N 4N1 Canada

${ }^{2}$ Corresponding author

s.borgland@ucalgary.ca

Running title: Optogenetic stimulation of LH orexin/dynorphin in the VTA

\title{
Number of Figures: 5
}

Number of supplemental figures: 2

Word Count: Abstract 227, Introduction 476, Discussion 1264 (Main: 5257)

Key words: Ventral tegmental area, dopamine, orexin, hypocretin, incentive value, reward, optogenetics 


\section{ABSTRACT}

Reward and reinforcement processes are critical for survival and propagation of genes. While numerous brain systems underlie these processes, a cardinal role is ascribed to mesolimbic dopamine. However, ventral tegmental area (VTA) dopamine neurons receive complex innervation and various neuromodulatory factors, including input from lateral hypothalamic orexin/hypocretin neurons which also express and co-release the neuropeptide, dynorphin $\left(\mathrm{LH}_{\mathrm{ox} / \mathrm{dyn}}\right)$. Dynorphin in the VTA induces aversive conditioning through the Kappa opioid receptor (KOR) and decreases dopamine when administered intra-VTA. Exogenous application of orexin or orexin 1 receptor (oxR1) antagonists in the VTA bidirectionally modulates dopamine-driven motivation and reward-seeking behaviours, including the attribution of motivational value to primary rewards and associated conditioned stimuli. However, the effect of endogenous stimulation of $\mathrm{LH}_{\mathrm{ox} / \mathrm{d} y \mathrm{n}}$-containing projections to the VTA and the potential contribution of co-released dynorphin on mesolimbic dopamine and reward related processes remains uncharacterised. We combined optogenetic, electrochemical, and behavioural approaches to examine this. We found that optical stimulation of $\mathrm{LH}_{\mathrm{ox} / \mathrm{dyn}}$ inputs in the VTA potentiates mesolimbic dopamine neurotransmission in the nucleus accumbens (NAc) core, produces real time and conditioned place preference, and increases the food cue-directed orientation in a Pavlovian conditioning paradigm. $\mathrm{LH}_{\mathrm{ox} / \mathrm{dyn}}$ potentiation of NAc dopamine release and real time place preference was blocked by an oxR1, but not KOR antagonist. Thus, rewarding effects associated with optical stimulation of $\mathrm{LH}_{\mathrm{ox} / \mathrm{dyn}}$ inputs in the VTA are predominantly driven by orexin rather than dynorphin. 


\section{INTRODUCTION}

Ventral tegmental area (VTA) dopamine neurons are involved in motivated survival behaviours and their activity can influence positive and negative reinforcement, incentive salience, and aversion[1-4]. These varied functions are guided by various subpopulations of VTA dopamine neurons [5], efferent projections of dopamine neurons to different regions [68], different neuromodulatory afferents to dopamine neurons [5,9-11], or a combination of these factors. Mesolimbic dopamine projections from the VTA to the nucleus accumbens (NAc) energize behaviour toward motivationally relevant cues[12,13]. However, factors that modulate and direct mesolimbic dopamine in relation to motivated behaviour are complex and not fully understood.

One factor that modulates mesolimbic dopamine neuronal activity, plasticity and reward-seeking is the lateral hypothalamic (LH) peptide, orexin (ox, or hypocretin [14]). Orexin $\mathrm{A}$ and $\mathrm{B}$ are synthesized in the $\mathrm{LH}$ area and project to cortical and subcortical brain structures [15-17]. The VTA receives en passant $\mathrm{LH}$ ox-containing fibres $\left(\mathrm{LH}_{\mathrm{ox} / \mathrm{dyn}}\right)$ with close appositions to VTA dopamine neurons $[15,18,19]$. Although these fibres are present in the VTA, less than $5 \%$ show identifiable synaptic specializations [18]. However, most axons in the VTA stain heavily for dense core vesicles[18], suggesting that, similar to other neuropeptides, ox release in the VTA is largely extrasynaptic. LH ox-containing neurons are highly co-localized with dynorphin (dyn) [20], the endogenous ligand of kappa opioid receptors (KOR). Co-expression is observed in dense core vesicles, suggesting that these peptides may be co-released $[21,22]$. Indeed, corelease of ox and dyn within the LH have opposing actions on firing of local neurons [22]. Similarly, exogenous ox application to VTA slices increases firing of dopamine neurons 
projecting to the NAc shell, but not the basolateral amygdala, whereas bath application of dyn has the opposite effect, suggesting a distinct role for ox in promoting VTA-NAc dopamine activity [10]. While ox in the VTA augments reward-seeking and motivated behaviours through activation of orexin receptor 1 (oxR1) [23-27], dyn in the VTA inhibits reward-seeking and produces conditioned place aversion $[28,29]$ and reduced dopamine [30]. OxR1 antagonism in the VTA decreases cocaine self-administration and LH-self-stimulation, both which are reversed by blocking KORs. Thus, it has been proposed that ox signaling can occlude the reward threshold-elevating effects of co-released dyn and thereby facilitate reward-seeking [21]. While $\mathrm{LH}_{\mathrm{ox}}$ inputs provide the only source of ox to the VTA, several brain nuclei have dyn-containing neurons [31,32], with significant dyn-containing projections from the NAc to the VTA [33]. Because application of intra-VTA norBNI inhibits actions of dyn from all sources, it is unknown what the direct contribution of dyn from the LH input to reward-seeking behaviour. Furthermore, it is unknown if endogenous $\mathrm{LH}_{\mathrm{ox} / \mathrm{dyn}}$ action in the VTA can influence mesolimbic dopamine neurotransmission and motivational processes that guide reward-seeking. In this study, we systematically tested whether optical stimulation of $\mathrm{LH}_{\mathrm{ox} / \mathrm{dyn}}$ afferents in the VTA promotes NAC dopamine release, reward-seeking behaviours, and/or increases the incentive value of food.

\section{BRIEF METHODS}

\section{Subjects}

Adult male and female orexin-EGFP-2A-cre (orexin-cre) mice (post-natal day 60-90; originally from the Yamanaka lab at the Nagoya University [34]) were bred locally at the University of 
Calgary Clara Christie Center for Mouse Genomics. All mice received bilateral infusions of either channelrhodopsin ('ChR2') (AAV2/8-EF1a-DIO-hChR2(H134R)-mCherry; Neurophotonics, Centre de Recherche CERVO, Quebec City, QC, Canada) or control ('mCherry') (AAV2/8-hSyn-DIOmCherry; Neurophotonics) virus. Mice included in behavioural experiments received a second surgery to implant optical fibres targeted at the VTA, 6 weeks after viral infusions. All experimental procedures adhered to ethical guidelines established by the Canadian Council for Animal Care and animal use protocols approved by the University of Calgary Animal Care and Use Committee.

\section{Real-Time Place Preference (RTPP)}

Orexin-cre ChR2 $(n=8)$ and Orexin-cre mCherry $(n=10)$ mice implanted with bilateral optical fibres underwent 3 stages of real-time place preference paradigm (Figure 1A, C; see supplemental materials for detailed description). Briefly, all mice were allowed to explore a 2chamber arena with no overt features while receiving no stimulation to assess baseline preference for either chamber. Next, all mice underwent 3 days of stimulation sessions where one chamber of the arena (counterbalanced across mice) was paired with optical stimulation of

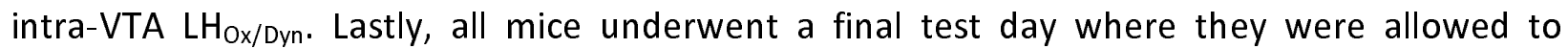
explore the arena, again with no stimulation. Data were collected and laser stimulation (473 $\mathrm{nm}, 20 \mathrm{~Hz}, 5 \mathrm{~mW}, 5 \mathrm{~ms}$ pulses, $1 \mathrm{~s}$ duration) triggered using EthoVision XT software (Noldus Information Technology, Wageningen, Netherlands).

For the experiment involving the oxR1 antagonist, SB-334867, or the KOR antagonist, nor BNI male and female orexin-cre mice were infused with ChR2 ( $n=10$ for SB-334867 and $n=12$ 
for norBNI) in LH and implanted with optical fibres targeted at the VTA. Mice underwent RTPP as above. However, prior to each conditioning session (day 2-4), all mice received an intraperitoneal injection of either SB-334867 ( $\mathrm{n}=5,15 \mathrm{mg} / \mathrm{kg}$ ) (Hello Bio Inc., Princeton, NJ, USA; dissolved in vehicle $10 \%$ hydroxypropyl-beta-cyclodextrin (HPBCD) and $2 \%$ dimethyl sulfoxide (DMSO) in sterile water w/v) or vehicle $(n=5)$, or norBNI $(n=5,15 \mathrm{mg} / \mathrm{kg})$ or vehicle ( $n=7) 15$ min prior to being placed into the arena.

\section{In vivo Fast-Scan Cyclic Voltammetry (FSCV)}

Mice (ChR2 $n=7 ;$ mCherry $n=7$ ) were anaesthetized with an intraperitoneal injection of $25 \%$ urethane $(1.0-1.5 \mathrm{~g} / \mathrm{kg})$ dissolved in sterile saline. Small craniotomies were made above the $\mathrm{NAc}(\mathrm{AP}+1.0 ; \mathrm{ML}+1.0)$ and the VTA (AP -3.5; $\mathrm{ML}+0.5)$ and contralateral cortex $(\mathrm{AP}+1.8 ; \mathrm{ML}$ 2.0). A chlorinated silver wire $(\mathrm{Ag} / \mathrm{AgCl})$ reference electrode was implanted in the contralateral cortex (DV -0.8) and cemented in place (C\&B metabond, as above). Recording (targeted at right NAc core) and stimulating (combined with optical fibre; targeted at VTA) were slowly lowered to desired locations. FSCV data were collected in $120 \mathrm{~s}$ files, with stimulation onset occurring $5 \mathrm{~s}$ into the recording using TarHeel CV (ESA Biosciences Inc., Chelmsford, MA, USA) and HighDefinition Cyclic Voltammetry Suite (University of North Carolina, Chapel Hill). 10 recordings of electrical stimulation $(60 \mathrm{~Hz}, 60$ pulses; $120 \mathrm{uA}), 10$ recordings of optical stimulation (laser as above; $473 \mathrm{~nm}, 20 \mathrm{~Hz}, 20 \mathrm{~mW}$, 5-ms pulses, 1s duration), and 10 recording of combine electrical (as above) and optical stimulation (as above) were made in a counter-balanced order across subjects. See supplemental materials for detailed methods. Data were analysed using chemometric analysis, principal component regression, and residual analyses in TarHeel and 
HDCV (as above; [35]) to calculate the peak dopamine and area under the curve for $10 \mathrm{~s}$ period following stimulation onset. Data were compared between electrical, laser, and combined electrical-laser stimulation to determine the effect of $\mathrm{LH}_{\mathrm{ox} / \mathrm{dyn}}$-VTA stimulation on mesolimbic dopamine neurotransmission.

For SB-334867 (ChR2 $n=7$; mCherry $n=7$ ) or norBNI (ChR2 $n=6$; mCherry $n=5$ ) injections, we conducted anaesthetised FSCV data acquisition as above, followed by an intraperitoneal injection of SB-334867 (15 mg/kg) or norBNI (15 mg/kg). After $15 \mathrm{~min}$, we recorded evoked responses to electrical stimulation and to electrical + optical stimulation and compared the area under the curve and peak dopamine concentration to recordings made prior to administration of the antagonist.

\section{Electrophysiology}

All electrophysiological recordings were performed in slice preparations from adult male and female orexin-cre mice (at least 4 months old) that were injected with either rAAV2-EF1a-DIOhCHR2(H134R)-eYFP (firing experiments, Supplemental Figure 1) or AAV2/8-hSyn-DIOhChR2(H134R)-mCherry (EPSC experiments, Figure 5) into the LH (as above) 6 weeks prior to patch clamp recordings. Dopamine neurons from the lateral VTA located medial to the medial terminal (MT) nucleus of the accessory optic tract were identified by morphology, presence of $\mathrm{H}$-current, and post-hoc labeling for tyrosine hydroxylase. Briefly, mice were anaesthetized with isoflurane and transcardially perfused with an ice-cold $\mathrm{N}$-methyl-d-glucamine (NMDG) solution containing (in mM): $93 \mathrm{NMDG}, 2.5 \mathrm{KCl}, 1.2 \mathrm{NaH} 2 \mathrm{PO} 4.2 \mathrm{H} 2 \mathrm{O}, 30 \mathrm{NaHCO}, 20 \mathrm{HEPES}, 25$ D-glucose, 5 sodium ascorbate, 3 sodium pyruvate, 2 thiourea, $10 \mathrm{MgSO} 4.7 \mathrm{H} 2 \mathrm{O}$ and 0.5 
$\mathrm{CaCl} 2.2 \mathrm{H} 2 \mathrm{O}$ and saturated with $95 \% \mathrm{O} 2-5 \% \mathrm{CO} 2$. Mice were then decapitated, and brains were extracted. Horizontal sections $(250 \mu \mathrm{m})$ containing the VTA were cut on a vibratome (Leica, Nussloch, Germany). Slices were then incubated in NMDG solution $\left(32^{\circ} \mathrm{C}\right)$ and saturated with $95 \%$ O2-5\% CO2 for $10 \mathrm{~min}$. Following this, the slices were transferred to artificial cerebrospinal fluid (aCSF) containing (in mM): $126 \mathrm{NaCl}, 1.6 \mathrm{KCl}, 1.1 \mathrm{NaH} 2 \mathrm{PO} 4,1.4 \mathrm{MgCl} 2,2.4$ $\mathrm{CaCl} 2,26 \mathrm{NaHCO} 3$ and 11 glucose $\left(32-34^{\circ} \mathrm{C}\right)$ and saturated with $95 \% \mathrm{O} 2-5 \% \mathrm{CO} 2$ and incubated in a holding chamber for at least 45 minutes before being transferred to a recording chamber. Cells were visualized on an upright microscope using "Dodt-type" gradient contrast infrared optics and whole-cell recordings were made using a MultiClamp 700B amplifier (Axon Instruments, Union City, CA). Recording electrodes (3-5 MS) for measuring evoked firing were filled with potassium-D-gluconate internal solution (in $\mathrm{mM}$ ): 136 potassium-D-gluconate, 4 MgCl2, 1.1 HEPES, 5, EGTA, 10 sodium creatine phosphate, 3.4 Mg-ATP and 0.1 Na2GTP and $0.2 \%$ biocytin. The membrane potential for each neuron was set to $-60 \mathrm{mV}$ by $\mathrm{DC}$ injection via the patch amplifier and a series of 5 current pulses (250 ms in duration, 5-25 pA apart, adjusted for each cell) were applied every 45 seconds, where the minimum current amplitude was set for each cell so that the first pulse was subthreshold and did not yield firing. We optogenetically stimulated LH inputs over a range of frequencies $(5,20$ or $30 \mathrm{~Hz}$ for $10 \mathrm{~s})$ from a light-emitting diode (LED) blue light source $(470 \mathrm{~nm})$ directly delivered the light path through the Olympus $40 \mathrm{X}$ water immersion lens.

Recording electrodes (3-5 M 2 ) for measuring evoked EPSCs were filled with CeMeSO3 internal solution containing (in mM): 117 CeMeSO3, $2.8 \mathrm{NaCl}, 20 \mathrm{HEPES}, 0.4$ EGTA, 5 TEA, 5 MgATP and 0.5 NaGTP and $0.2 \%$ biocytin. For AMPA EPSC recordings, neurons were held at -70 
$\mathrm{mV}$ in the presence of picrotoxin $(100 \mu \mathrm{M})$ and $470 \mathrm{~nm}$ LED light flashes (1s) were used to attempt to evoke EPSCs. For evoked NMDA EPSCs, recorded at $+40 \mathrm{mV}$, a bipolar tungstenstimulating electrode was placed $100-300 \mu \mathrm{m}$ rostral to the cell being recorded and stimulated at $0.1 \mathrm{~Hz}$ in the presence of $100 \mu \mathrm{M}$ picrotoxin and $10 \mu \mathrm{M}$ DNQX to block to block $\mathrm{GABA}_{\mathrm{A}}$ and AMPA receptors respectively. NMDAR EPSCs were filtered at $2 \mathrm{kHz}$, digitized at 5-10 kHz. After obtaining a minimum 5 min stable baseline of evoked NMDA EPSCs, we optogenetically stimulated LH inputs in the VTA at $20 \mathrm{~Hz}$ for $10 \mathrm{~s}$ from a light-emitting diode (LED) blue light source $(470 \mathrm{~nm})$ directly delivered the light path through the Olympus $40 \mathrm{X}$ water immersion lens. SB-334867 and norBNI (Tocris) stock solutions were both dissolved in 100\% DMSO and were bath applied at $1 \mu \mathrm{M}$ in $0.01 \%$ DMSO throughout the experiment. $\mathrm{N}$-methyl-D-aspartate (NMDA) traces were averages of 12 sweeps (120 s) before and 7 min after optogenetic stimulation. Data were averaged in 5 min bins, normalized to baseline, which is defined as the average EPSC amplitude of 5 min before stimulation, and presented as average across cells \pm SEM.

\section{Histology}

Viral transfection, optical fibre, electrode placement, recorded biocytin-labeled dopamine neurons, and colocalization of orexin neurons and viral transfections were checked retrospectively for all mice. See supplemental materials for detailed description of histology.

\section{Statistics}


All statistical analyses were completed using GraphPad Prism 8 or 9 and described in the figure legends. All values are expressed as mean \pm standard error of the mean (SEM). The alpha risk for the rejection of the null hypothesis was set to 0.05 . All data met criteria for normality unless otherwise specified. All post hoc tests were conducted with Sidak's correction for multiple comparisons, unless otherwise stated.

\section{RESULTS}

We first determined the window of efficacy for reliable optical control of ChR2expressing $\mathrm{LH}_{\mathrm{ox} / \mathrm{dyn}}$ neuronal activity ex vivo. Using whole-cell patch recordings, we confirmed the selectivity of the floxed-AAV-cre strategy to genetically target the expression of ChR2 to $\mathrm{LH}_{\mathrm{ox} / \mathrm{dyn}}$ neurons and the reliability of photocurrents in ChR2-expressing $\mathrm{LH}_{\mathrm{ox} / \mathrm{dyn}}$ neurons over a wide range of frequencies $(1-100 \mathrm{~Hz})$ (Supplemental Figure 1A-D). These results indicate that $\mathrm{LH}_{\mathrm{ox} / \mathrm{dyn}}$ neurons can be reliably activated by photostimulation. We next identified the frequency of optical stimulation of $\mathrm{LH}_{\mathrm{ox} / \mathrm{d} y n}$ inputs that would influence firing activity of VTA dopamine neurons (Supplemental Figure 1E). A $20 \mathrm{~Hz}$ stimulation of $\mathrm{LH}_{\mathrm{ox} / \mathrm{dyn}}$ inputs in the VTA could increase firing of dopamine neurons and used this frequency for in vivo experiments (Supplemental Figure 1F).

\section{Endogenous $\mathrm{LH}_{\mathrm{ox} / \mathrm{dyn}}$ release in the VTA promotes place preference}

To examine our hypothesis that optogenetic stimulation of $\mathrm{LH}_{\mathrm{ox} / \mathrm{dyn}}$ inputs in the VTA would promote preference (Figure $1 A-D$ ), we used a real-time place preference (RTPP) paradigm, whereby time spent in one of the compartments is paired with intra-VTA 
optogenetic stimulation of $\mathrm{LH}_{\mathrm{ox} / \mathrm{dyn}}$ inputs. In the absence of stimulation, there was no significant baseline preference for either compartment displayed by mCherry control or ChR2 expressing mice (Figure 1E). Furthermore, mCherry mice did not develop a significant preference for either compartment of the apparatus over the three stimulation sessions of RTPP (Figure 1E). However, the ChR2 mice demonstrated a significant preference for the compartment paired with intra-VTA $\mathrm{LH}_{\mathrm{ox} / \mathrm{dyn}}$ stimulation over the 3 stimulation days (Figure 1E, F). ChR2 mice spent significantly more time in the stimulation compartment compared to the non-stimulation compartment on days 2 and 3.

To determine if intra-VTA photostimulation of $\mathrm{LH}_{\mathrm{ox} / \mathrm{dyn}}$ can influence associative learning mechanisms, we next examined whether mCherry or ChR2 mice demonstrated a preference for either compartment in the absence of optical stimulation in a subsequent session. While the mCherry mice did not show a significant preference for either compartment, the ChR2 mice spent significantly more time in the compartment previously paired with stimulation (Figure 1E). Thus, $\mathrm{LH}_{\mathrm{ox} / \mathrm{dyn}}$ in the VTA can induce rewarding effects upon stimulation as well as form associative memories related to it.

To assess if locomotor activity was influenced by stimulation, we compared total distance travelled, which did not differ between the mCherry $(8.6 \pm 1.5 \mathrm{~m})$ and ChR2 $(6.0 \pm 2$. $6 \mathrm{~m})$ groups $(t(14)=1.730, p=0.1056)$. Velocity also did not differ between mCherry $(0.0026 \pm$ $0.00055 \mathrm{~m} / \mathrm{s})$ and ChR2 $(0.0017 \pm 0.00055 \mathrm{~m} / \mathrm{s})$ mice $(t(7)=1.6, p=0.161)$. We then examined whether locomotor activity differed between mCherry and ChR2 mice in each compartment. A 2-way ANOVA showed that distance travelled in the stimulation ON or stimulation OFF compartments did not significantly differ (Figure 1G). Velocity also did not differ between 
stimulation ON or stimulation OFF chambers (Figure $1 \mathrm{H}$ ). Thus, intra-VTA optical stimulation of $\mathrm{LH}_{\mathrm{ox} / \mathrm{dyn}}$ produced a preference for the compartment paired with stimulation, without influencing locomotor activity, suggesting that $\mathrm{LH}_{\mathrm{ox} / \mathrm{dyn}}$ in the VTA can promote contingent learning.

As $\mathrm{LH}_{\mathrm{ox} / \mathrm{dyn}}$-containing neurons corelease the inhibitory neuropeptide dyn $[20,21]$ and the fast-acting neurotransmitter glutamate with ox [36], we first examined the role of oxR1 signalling using the oxR1 antagonist SB-334867, in the RTPP paradigm. As in Figure 1, ChR2 mice did not show a significant preference for either compartment prior to stimulation sessions (Figure 2A). Across subsequent conditioning sessions, the vehicle group developed a significant preference for the compartment paired with $\mathrm{LH}_{\mathrm{ox} / \mathrm{dyn}}$ stimulation in the VTA. Whereas, the SB334867 group, treated prior to each conditioning session, did not develop a significant preference for either compartment (Figure 2A,B).

To determine if SB-334867 influenced locomotor activity in either compartment, we measured distance travelled and velocity. There was a significant main effect of SB-334867 on distance travelled, but no interaction between drug and compartment, suggesting that the influence of SB-334867 on locomotor activity did not have differential effects in the stimulation ON or OFF compartment (Figure 2C). Administration of SB-334867 had a significant effect on velocity, but this was not different between stimulation ON and OFF compartments (Figure 2D). Lastly, in the post-stimulation test session, mice injected with vehicle spent significantly more time in the paired compartment compared to the unpaired compartment, whereas the mice given SB-334867 showed no significant preference for either compartment (Figure 2A). 
Thus, inhibition of oxR1 signalling prevented both the development of preference for $\mathrm{LH}_{\mathrm{ox} / \mathrm{dyn}}$ optical stimulation in the VTA as well as its associated memory.

To examine the contribution of $\mathrm{LH}_{\mathrm{dyn}}$ from optically stimulated $\mathrm{LH}_{\mathrm{ox} / \mathrm{dyn}}$ inputs in the VTA to RTPP, we used the KOR antagonist, norBNI prior to each conditioning session. ChR2 mice did not show a significant preference for either compartment prior to stimulation sessions (Figure 2E). Across subsequent conditioning sessions, the vehicle group or the norBNI groups developed a significant preference for the compartment paired with $\mathrm{LH}_{\mathrm{ox} / \mathrm{dyn}}$ stimulation in the VTA (Figure 2E,F).

To determine if norBNI influenced locomotor activity in either compartment, we measured distance travelled and velocity. There was no effect of norBNI on distance travelled in either stimulation compartment (Figure 2G). Administration of norBNI had a significant effect on velocity, but this was not different between stimulation ON and OFF compartments (Figure 2H).

Lastly, in the post-stimulation test session, mice injected with vehicle spent significantly more time in the paired compartment compared to the unpaired compartment, whereas the mice given norBNI showed no significant preference for either compartment (Figure 2E). Taken together, inhibition of KOR signalling did not influence preference for $\mathrm{LH}_{\mathrm{ox} / \mathrm{dyn}}$ optical stimulation in the VTA. However, the ability to recall this preference was inhibited by norBNI.

\section{Endogenous $\mathrm{LH}_{\mathrm{ox} / \mathrm{dyn}}$ release in the VTA promotes approach to a Pavlovian food cue.}

To test if optical stimulation of $\mathrm{LH}_{\mathrm{ox} / \mathrm{dyn}}$ in the VTA influences the incentive value of food cues, we used a Pavlovian conditioning paradigm where $\mathrm{LH}_{\mathrm{ox} / \mathrm{dyn}}$ inputs were stimulated upon 
delivery of the conditioned stimulus predicting food pellets (Supplemental Figure 2A). We first determined the baseline cue evaluation without optical stimulation. There was no significant difference between the number of lever presses made for presentation of the novel compound light-tone food cue between mCherry $(7.7 \pm 2.9$ presses $)$ and ChR2 mice $(5.4 \pm 2.3$ presses $)$ $(t(16)=0.795, p=0.419)$. Next, we examined the number of conditioned responses by quantifying magazine and food cue approaches during food cue presentation across days. Optical stimulation of $\mathrm{LH}_{\mathrm{ox} / \mathrm{dyn}}$ inputs to the VTA of ChR2 mice showed significantly more orienting to the cue compared to mCherry mice (Supplemental Figure 1B). There was no significant difference between mCherry and ChR2 mice in the number of approaches to the magazine during the cue (Supplemental Figure 2C). We also compared the effect of optical stimulation on entries into the magazine without food cue presentation. Both ChR2 and mCherry mice significantly decreased non-CS magazine entries across conditioning days but this did not differ between mCherry and ChR2 mice (Supplemental Figure 2D). These results indicate that both mCherry and ChR2 mice learned the predictive cue value, but the optical stimulation of $\mathrm{LH}_{\mathrm{ox} / \mathrm{dyn}}$ inputs to the VTA increased orientation to the food cue.

We next assessed whether intra-VTA optical stimulation of $\mathrm{LH}_{\mathrm{ox} / \mathrm{d} y n}$ inputs during Pavlovian conditioning influenced cue value by comparing the number of cue presentations received in the pre-conditioning cue value assessment and post-conditioning cue value test session. All mice receive significantly more cue presentations during the post-conditioning test session compared to pre-conditioning baseline, however, there was no effect of optogenetic stimulation of $\mathrm{LH}_{\mathrm{ox} / \mathrm{dyn}}$ on the number of cue presentations (Supplemental Figure 1E). Next, we examined the number of lever presses made for presentation of the food cue with the baseline 
prior to conditioning. While all mice significantly increased lever presses made for the cue after conditioning, there was no difference between mCherry or ChR2 mice (Supplemental Figure Figure 1F). To determine if the value of the primary reward changed with intra-VTA optical stimulation of $\mathrm{LH}_{\mathrm{ox} / \mathrm{dyn}}$ inputs, we examined home cage sucrose consumed without stimulation (Supplemental Figure 1A,G). Sucrose consumption during the baseline and post-conditioning tests did not differ significantly between mCherry $(0.029 \pm 0.01 \mathrm{KCal} / \mathrm{g})$ and ChR2 mice $(0.041$ $\pm 0.014 \mathrm{KCal} / \mathrm{g}$ ) (Supplemental Figure 1G). Thus, optical stimulation of $\mathrm{LH}_{\mathrm{ox} / \mathrm{dyn}}$ inputs in the VTA during Pavlovian conditioning did not influence the value of the primary food reward.

Endogenous $\mathrm{LH}_{\mathrm{ox} / \mathrm{dyn}}$ in the VTA release potentiates electrically evoked mesolimbic dopamine neurotransmission

Given that phasic optical stimulation of VTA dopamine neurons induces RTPP [37] and increased dopamine underlies incentive motivation [1], we next determined whether optical stimulation of $\mathrm{LH}_{\mathrm{ox} / \mathrm{dyn}}$ inputs in the VTA could influence dopamine concentration using in vivo FSCV. Exogenous application of ox in the VTA increases dopamine release [25], whereas systemic oxR1 antagonists inhibit cocaine-evoked dopamine [24]. However, it is unknown how optogenetic stimulation of $\mathrm{LH}_{\mathrm{ox} / \mathrm{dyn}}$ inputs in the VTA can influence dopamine in the NAc. To examine whether optical stimulation of $\mathrm{LH}_{\mathrm{ox} / \mathrm{dyn}}$ inputs to the VTA could modulate electricallyevoked dopamine neurotransmission (Figure 3A, B), we electrically stimulated dopamine release with or without intra-VTA optical stimulation of $\mathrm{LH}_{\mathrm{ox} / \mathrm{dyn}}$ inputs (Figure $3 \mathrm{C}-\mathrm{E}$ ). Without optical stimulation, electrically-evoked stimulation was not significantly different between mCherry $(1.42 \pm 0.54 \mu \mathrm{M})$ and ChR2 mice $(2.28 \pm 0.86 \mu \mathrm{M})(t(13)=1.575, p=0.1393)$. 
There was a significant effect of virus and optical stimulation on evoked dopamine concentration. While there was no significant potentiation of evoked dopamine peak (Figure 3F) or area under the curve (AUC) (Figure 3G) with laser stimulation of $\mathrm{LH}_{\mathrm{ox} / \mathrm{dyn}}$ inputs in the VTA of mCherry mice, peak evoked dopamine concentration (Figure 3F) or AUC (Figure 3E) was significantly potentiated by laser stimulation in ChR2 mice. We also tested if optical stimulation of intra-VTA of $\mathrm{LH}_{\mathrm{ox} / \mathrm{dyn}}$ inputs alone can evoke dopamine in the NAc core. Optical stimulation did not significantly alter NAC dopamine concentration (AUC) for the $10 \mathrm{~s}$ after stimulus offset in either mCherry $\left(0.30 \pm 0.16 \mu \mathrm{M}^{2}\right)$ or ChR2 mice $\left(0.076 \pm 0.22 \mu \mathrm{M}^{2}\right)(t(12)=1.363, p=$ 0.1979) (Figure 3D). Taken together, Intra-VTA optical stimulation of $\mathrm{LH}_{\mathrm{ox} / \mathrm{dyn}}$ inputs alone is insufficient to drive dopamine release in the NAc. However, optogenetic stimulation of $\mathrm{LH}_{\mathrm{ox} / \mathrm{dyn}}$ inputs in the VTA significantly potentiated electrically-evoked dopamine neurotransmission in ChR2, but not mCherry mice.

To examine whether evoked dopamine concentration potentiation by intra-VTA optical stimulation of $\mathrm{LH}_{\mathrm{ox} / \mathrm{dyn}}$ inputs was mediated by oxR1 signalling, we measured the effect of the oxR1 antagonist, SB-334867, on evoked dopamine neurotransmission with or without $\mathrm{LH}_{\mathrm{ox} / \mathrm{dyn}}$ stimulation in the VTA of ChR2 or mCherry mice (Figure 4A-D). Before SB-334867, optical stimulation of evoked dopamine influenced peak concentration (Figure 4Ci) or AUC (Figure 4Di) in the NAC of ChR2, but not mCherry mice. After SB-334867, optical stimulation did not significantly alter evoked peak dopamine concentration in the NAC or AUC of either mCherry or ChR2 mice (Figure 4Cii, 4Dii). Taken together, potentiation of NAc dopamine by stimulation of $\mathrm{LH}_{\mathrm{ox} / \mathrm{dyn}}$ inputs to the VTA was blocked by administration of SB-334867. 
Next, we tested whether evoked dopamine concentration potentiation by intra-VTA optical stimulation of $\mathrm{LH}_{\mathrm{ox} / \mathrm{dyn}}$ inputs was influenced by KOR signalling. We measured the effect of norBNI on evoked dopamine neurotransmission with or without $\mathrm{LH}_{\mathrm{ox} / \mathrm{dyn}}$ stimulation in the VTA of ChR2 or mCherry mice (Figure 4E-G). Before norBNI, optical stimulation of evoked dopamine influenced peak concentration (Figure 4Ei) or AUC (Figure 4Fi) in the NAC of ChR2, but not mCherry mice. After norBNI, optical stimulation significantly increased evoked peak dopamine concentration in the NAc of ChR2, but not mCherry mice. Taken together, potentiation of NAc dopamine by stimulation of $\mathrm{LH}_{\mathrm{ox} / \mathrm{dyn}}$ inputs to the VTA is not significantly altered by administration of norBNI, suggesting that dyn does not contribute to $\mathrm{LH}_{\mathrm{ox} / \mathrm{dyn}}$ in the VTA-mediated potentiation of NAc dopamine.

$\mathrm{LH}_{\mathrm{ox} / \mathrm{dyn}}$ neurons are also known to express vesicular glutamate transporter 1 and 2 [36] and optical stimulation of these neurons in the LH can evoke AMPA excitatory postsynaptic currents (EPSCS) onto histaminergic neurons [38,39]. Therefore, we wanted to determine whether optical stimulation of $\mathrm{LH}_{\mathrm{ox} / \mathrm{dyn}}$ inputs in the VTA could evoke AMPA EPSCs. However, we found that optical stimulation of $\mathrm{LH}_{\mathrm{ox} / \mathrm{dyn}}$ input in the VTA did not evoke AMPA EPSCs recorded at $-70 \mathrm{mV}$ (data not shown). Given that exogenous application of ox can potentiate electrically evoked NMDA currents onto VTA dopamine neurons $[26,40]$, we next tested if optical stimulation of $\mathrm{LH}_{\mathrm{ox} / \mathrm{dyn}}$ inputs to the VTA could potentiate NMDA currents of dopamine neurons. Optical stimulation of $\mathrm{LH}_{\mathrm{ox} / \mathrm{dyn}}$ inputs potentiated electrically evoked NMDA currents onto dopamine neurons (Figure 5A-C). However, pre-application of SB-334867 and norBNI blocked the potentiation of NMDA currents by optical stimulation and induced a depression of evoked NMDA EPSCS (Figure 5D-F). Taken together, while optical stimulation of $\mathrm{LH}_{\mathrm{ox} / \mathrm{dyn}}$ inputs in the 
VTA does not produce an excitatory synaptic current onto dopamine neurons alone, it can potentiate existing excitatory synaptic currents via a neuromodulatory effect.

\section{DISCUSSION}

Here, we found that endogenous $\mathrm{LH}_{\mathrm{ox} / \mathrm{dyn}}$ release in the VTA significantly potentiates evoked mesolimbic dopamine neurotransmission, an effect dependent on oxR1, but not KOR signaling. Furthermore, optical stimulation of $\mathrm{LH}_{\mathrm{ox} / \mathrm{dyn}}$ in the VTA can produce place preference that is also observed after cessation of optical stimulation, consistent with previous work demonstrating that systemic SB-334867 can inhibit the expression of conditioned place preference (CPP) for food[41] or drugs of abuse[14,23]. During optical stimulation of $\mathrm{LH}_{\mathrm{ox} / \mathrm{dyn}}$ in the VTA, orientations to a Pavlovian food cue is enhanced, a key motivational feature of reward cues. Finally, while optical stimulation of $\mathrm{LH}_{\mathrm{ox} / \mathrm{dyn}}$ into the VTA alone did not produce EPSCs, it potentiated evoked NMDA EPSCs, suggesting a neuromodulatory role in driving these behaviours. Thus, $\mathrm{LH}_{\mathrm{ox} / \mathrm{dyn}}$ in the VTA may promote motivated reward-seeking behaviours through potentiating excitatory synaptic transmission in the VTA and NAc dopamine.

Our results extend previous work demonstrating that exogenously applied ox in the VTA increases striatal dopamine. Inhibition of oxR1 in the VTA disrupts cocaine-potentiated evoked phasic dopamine release measured with FSCV in the rat caudate putamen [24]. Similarly, intraVTA orexin application augments dopamine [42] and potentiates cocaine-induced tonic dopamine release in rat NAC core measured with microdialysis [25]. Intra-VTA optical stimulation of $\mathrm{LH}_{\mathrm{ox} / \mathrm{dyn}}$ inputs alone was not sufficient to augment NAc dopamine but required phasic activation of VTA dopamine neurons to increase dopamine in the NAc core. Consistent 
with this, intra-VTA ox can increase phasically-evoked dopamine release in the caudate putamen with or without intravenous cocaine [25]. Previous studies have indicated that intraVTA KOR activation can suppress NAc dopamine and aversion learning [43] and that intra-VTA blockade of KORs disrupts the decrease in dopamine associated with an aversive stimulus [30]. This suggests that dyn released during aversive stimuli [44] decreases NAc dopamine through activation of KORs in the VTA [30]. However, inhibition of KORs during $\mathrm{LH}_{\mathrm{ox} / \mathrm{dyn}}$ optical stimulation did not alter phasically-evoked dopamine responses, suggesting that it is unlikely that the source of VTA dyn released with aversive stimuli is from $\mathrm{LH}_{\mathrm{ox} / \mathrm{dyn}}$ neurons. Consistent with this, intra-VTA administration of norBNI produced an effect on dopamine release in the medial prefrontal cortex but not the NAC $[45,46]$. Taken together, potentiation of phasic dopamine is driven by $\mathrm{LH}_{\mathrm{ox}}$ rather than $\mathrm{LH}_{\mathrm{dyn}}$ during optical stimulation of the $\mathrm{LH}_{\mathrm{ox} / \mathrm{dyn}}$ input to the VTA.

Glutamate is colocalized with $\mathrm{LH}_{\mathrm{ox} / \mathrm{dyn}}$ neurons [36] and could potentially be released into the VTA with optical stimulation, leading to enhanced dopamine release [47]. We found that optical stimulation of $\mathrm{LH}_{\mathrm{ox} / \mathrm{dyn}}$ inputs to the VTA did not produce an EPSC in the VTA, consistent with few synaptic contacts of $\mathrm{LH}_{\mathrm{ox} / \mathrm{dyn}}$ neurons onto dopamine neurons [18]. However, optical stimulation of $\mathrm{LH}_{\mathrm{ox} / \mathrm{d} y n}$ neurons potentiated evoked NMDA responses, suggesting a neuromodulatory effect of these peptides on excitatory synaptic transmission onto VTA dopamine neurons. Indeed, exogenously applied orexin in the VTA increases NMDA receptor currents and promotes synaptic plasticity of dopamine neurons [40]. As such, $\mathrm{LH}_{\mathrm{ox} / \mathrm{dyn}}$ may increase the gain of excitatory inputs onto VTA dopamine neurons. Given that NMDA receptor activation in the VTA is required for phasic dopamine $[47,48]$, $\mathrm{LH}_{\mathrm{ox} / \mathrm{dyn}}$ in the VTA may 
require coincident NMDA receptor activation, which likely occurs with $60 \mathrm{~Hz}$ stimulation, to potentiate NAc dopamine and thus impact reward processes that are dependent on mesolimbic dopamine.

Optical stimulation of $\mathrm{LH}_{\mathrm{ox} / \mathrm{dyn}}$ inputs in the VTA produced a strong place preference for a context paired with that stimulation. Continuous pairing of the intra-VTA $\mathrm{LH}_{\mathrm{ox} / \mathrm{dyn}}$ stimulation transformed a neutral stimulus (compartment) to a conditioned stimulus, whereby mice spent more time in the paired compartment. $\mathrm{LH}_{\mathrm{ox} / \mathrm{dyn}}$ stimulation in the VTA induced a progressive increase in preference for the paired compartment over the 3 pairing days in an oxR1dependent manner, suggesting that orexin action in the VTA plays a role in acquisition of this preference. Notably, SB33867 decreased general locomotor activity. However, this did not affect exploration of either compartment as mice explored both arenas equally, suggesting that the general effects of SB-334867 on locomotor activity did not impair the ability of mice to make an association with a rewarding compartment. Inhibition of oxR1 in the VTA increases reward thresholds for electrical self-stimulation, decreases impulsive responding on a 5-choice serial reaction time task, and decreases cocaine self-administration[21]. However, all of these effects are blocked by pretreatment with a KOR antagonist [21], suggesting that orexin in the VTA can negate the aversive effects of dynorphin. We tested if optically stimulated dyn release contributed to RTPP using the KOR inhibitor, norBNI. Others have demonstrated that pretreatment with a KOR agonist in the VTA potentiates preference for cocaine-associated contexts in a CPP paradigm $[49,50]$ and cocaine-evoked NAc dopamine [50]. However, we observed that norBNI did not influence the preference for optical stimulation of VTA $\mathrm{LH}_{\mathrm{ox} / \mathrm{dyn}}$ inputs or potentiation of evoked dopamine release. Taken together, rather than $\mathrm{LH}_{\mathrm{dyn}}$ acting 
presynaptically to disinhibit NAc core-projecting dopamine neurons, similar to cocaine, leading to potentiation of place preference or dopamine release, it is likely that $\mathrm{LH}_{\mathrm{ox} / \mathrm{dyn}}$ release may be modulating different circuits, with the effects of $\mathrm{LH}_{\mathrm{ox}}$ predominating in the VTA-NAC projection[10]. Thus, optical stimulation of $\mathrm{LH}_{\mathrm{ox} / \mathrm{dyn}}$ in the VTA is sufficient to produce a contextual preference in the absence of any tangible primary reward, suggesting that $\mathrm{LH}_{\mathrm{ox} / \mathrm{dyn}}$ stimulation in the VTA is critical for underlying reward-seeking behaviours.

24 hours after cessation of optical stimulation of $\mathrm{LH}_{\mathrm{ox} / \mathrm{dyn}}$ inputs in the VTA, a continued place preference was observed. This suggests a long-term encoding of a preference for the environment paired with endogenous ox release, rather than a transient behavioural influence of the stimulation itself. These data uphold previous findings that intra-VTA oxR1 signaling attenuates CPP to morphine or cocaine[23,42], suggesting that $\mathrm{LH}_{\mathrm{ox} / \mathrm{dyn}}$ in the VTA is sufficient for associating the context with both natural rewards and drugs of abuse. However, when KOR were blocked during the acquisition of the RTPP, the post-stimulation preference test was no longer significantly different from controls. Further research is required to test whether $\mathrm{LH}_{\mathrm{dyn}}$ release during the development of preference for intra-VTA $\mathrm{LH}_{\mathrm{ox} / \mathrm{dyn}}$ stimulation is required for the formation of this contextual association.

Because $\mathrm{LH}_{\mathrm{ox} / \mathrm{dyn}}$ in the VTA was necessary and sufficient for associating the context with preference for stimulation, we assessed if $\mathrm{LH}_{\mathrm{ox} / \mathrm{dyn}}$ in the VTA was involved in motivation towards a food reward and/or a Pavlovian food cue. Optical stimulation of $\mathrm{LH}_{\mathrm{ox} / \mathrm{dyn}}$ inputs in the VTA increased orientation to a food cue, suggesting that endogenous ox release in the VTA modulates the ability of food cues to direct reward-seeking behaviour. However, we did not observe any influence of prior $\mathrm{LH}_{\mathrm{ox} / \mathrm{dyn}}$ stimulation in the VTA on subsequent conditioned 
reinforcement behaviour, suggesting no enduring changes food cue incentive value in this paradigm. Furthermore, it is important to note that the conditioning effect we observed may in fact be to the rewarding features of $\mathrm{LH}_{\mathrm{ox} / \mathrm{dyn}}$ stimulation itself, rather than the sucrose per se. We did not observe changes in the incentive value of the primary reward, suggesting that $\mathrm{LH}_{\mathrm{ox} / \mathrm{dyn}}$ in the VTA is only implicated in the motivational processes relating to conditioned stimuli. This is an important finding as the role of cues in various behaviours, including aberrant motivational states such as addiction may directly involve ox signaling and thus provide a putative therapeutic target. In conclusion, this study demonstrates a significant role for endogenous ox release in the VTA in RTPP development and expression, food cue-directed motivation, and potentiation mesolimbic dopamine neurotransmission. Given that optical stimulation of $\mathrm{LH}_{\mathrm{ox} / \mathrm{dyn}}$ terminals in the VTA likely release dyn in addition to ox, our results demonstrate that the effects of ox predominate in mediating reward-seeking behaviour. These findings shift forward our understanding of neural circuitry underpinning reward-related processes and highlight that neuromodulation in distinct target regions may have independent or opposing effects. These findings not only contribute to our knowledge of general reward processes but, alongside previous work demonstrating a role for orexin in addiction, add support for targeting orexinergic systems as a possible treatment of addiction.

\section{Data accessibility}

Data will be made available upon request. 


\section{Acknowledgements}

The authors would like to acknowledge the Hotchkiss Brain Institute optogenetic core facility and the advanced microscopy facility for their technical support.

\section{Funding disclosure}

This work was supported by an NSERC Discovery grant (DG-343012 / DAS-04060 to S.L.B.) and a

Canada Research Chair (950-232211). C.S.T. was supported by an Alberta Academic Excellence

Graduate Studentship. A.M. was supported by a Mathison Centre for Research and Education

Postdoctoral Fellowship. The authors declare no competing financial interests.

\section{Author Contributions}

C.S.T. designed, performed and analyzed all experiments with supervision of S.L.B. M.R. and

A.M. performed and analyzed behavioural experiments with supervision of S.L.B and C.S.T.

M.Q. performed immunohistochemistry experiments. A.M. performed the electrophysiological

experiments in the VTA. C.B. performed electrophysiological recordings in the LH. C.S.T. and

S.L.B. wrote the manuscript and agree to be accountable for all aspects of the work.

\section{References}

1. Berridge KC. The debate over dopamine's role in reward: the case for incentive salience. Psychopharmacology (Berl). 2007;191:391-431.

2. Lammel S, Lim BK, Ran C, Huang KW, Betley MJ, Tye KM, et al. Input-specific control of reward and aversion in the ventral tegmental area. Nature. 2012;491:212-217.

3. Cohen JY, Haesler S, Vong L, Lowell BB, Uchida N. Neuron-type-specific signals for reward and punishment in the ventral tegmental area. Nature. 2012;482:85-88. 
4. Bromberg-Martin ES, Matsumoto M, Hikosaka O. Dopamine in motivational control: rewarding, aversive, and alerting. Neuron. 2010;68:815-834.

5. Morales M, Margolis EB. Ventral tegmental area: cellular heterogeneity, connectivity and behaviour. Nat Rev Neurosci. 2017;18:73-85.

6. Beier KT, Steinberg EE, DeLoach KE, Xie S, Miyamichi K, Schwarz L, et al. Circuit Architecture of VTA Dopamine Neurons Revealed by Systematic Input-Output Mapping. Cell. 2015;162:622-634.

7. Lammel S, Ion DI, Roeper J, Malenka RC. Projection-specific modulation of dopamine neuron synapses by aversive and rewarding stimuli. Neuron. 2011;70:855-862.

8. Lammel S, Hetzel A, Häckel O, Jones I, Liss B, Roeper J. Unique properties of mesoprefrontal neurons within a dual mesocorticolimbic dopamine system. Neuron. 2008;57:760-773.

9. Ford CP, Mark GP, Williams JT. Properties and opioid inhibition of mesolimbic dopamine neurons vary according to target location. J Neurosci. 2006;26:2788-2797.

10. Baimel C, Lau BK, Qiao M, Borgland SL. Projection-Target-Defined Effects of Orexin and Dynorphin on VTA Dopamine Neurons. Cell Rep. 2017;18:1346-1355.

11. Oliva I, Wanat MJ. Ventral Tegmental Area Afferents and Drug-Dependent Behaviors. Front Psychiatry. 2016;7:30.

12. Hamid AA, Pettibone JR, Mabrouk OS, Hetrick VL, Schmidt R, Vander Weele CM, et al. Mesolimbic dopamine signals the value of work. Nat Neurosci. 2016;19:117-126.

13. Walton ME, Bouret S. What Is the Relationship between Dopamine and Effort? Trends Neurosci. 2019;42:79-91.

14. Baimel C, Borgland SL. Hypocretin/Orexin and Plastic Adaptations Associated with Drug Abuse. Curr Top Behav Neurosci. 2017;33:283-304.

15. Peyron C, Tighe DK, van den Pol AN, de Lecea L, Heller HC, Sutcliffe JG, et al. Neurons containing hypocretin (orexin) project to multiple neuronal systems. J Neurosci. 1998;18:9996-10015.

16. de Lecea L, Kilduff TS, Peyron C, Gao X, Foye PE, Danielson PE, et al. The hypocretins: hypothalamus-specific peptides with neuroexcitatory activity. Proc Natl Acad Sci USA. 1998;95:322-327.

17. Sakurai T, Amemiya A, Ishii M, Matsuzaki I, Chemelli RM, Tanaka H, et al. Orexins and orexin receptors: a family of hypothalamic neuropeptides and $\mathrm{G}$ protein-coupled receptors that regulate feeding behavior. Cell. 1998;92:573-585.

18. Balcita-Pedicino JJ, Sesack SR. Orexin axons in the rat ventral tegmental area synapse infrequently onto dopamine and gamma-aminobutyric acid neurons. J Comp Neurol. 2007;503:668-684.

19. Fadel J, Deutch AY. Anatomical substrates of orexin-dopamine interactions: lateral hypothalamic projections to the ventral tegmental area. Neuroscience. 2002;111:379-387.

20. Chou TC, Lee CE, Lu J, Elmquist JK, Hara J, Willie JT, et al. Orexin (hypocretin) neurons contain dynorphin. J Neurosci. 2001;21:RC168.

21. Muschamp JW, Hollander JA, Thompson JL, Voren G, Hassinger LC, Onvani S, et al. Hypocretin (orexin) facilitates reward by attenuating the antireward effects of its cotransmitter dynorphin in ventral tegmental area. Proc Natl Acad Sci USA. 2014;111:E1648-1655. 
22. Li Y, van den Pol AN. Differential target-dependent actions of coexpressed inhibitory dynorphin and excitatory hypocretin/orexin neuropeptides. J Neurosci. 2006;26:1303713047.

23. Harris GC, Wimmer M, Aston-Jones G. A role for lateral hypothalamic orexin neurons in reward seeking. Nature. 2005;437:556-559.

24. España RA, Oleson EB, Locke JL, Brookshire BR, Roberts DCS, Jones SR. The hypocretin-orexin system regulates cocaine self-administration via actions on the mesolimbic dopamine system. Eur J Neurosci. 2010;31:336-348.

25. España RA, Melchior JR, Roberts DCS, Jones SR. Hypocretin 1/orexin A in the ventral tegmental area enhances dopamine responses to cocaine and promotes cocaine selfadministration. Psychopharmacology (Berl). 2011;214:415-426.

26. Borgland SL, Chang S-J, Bowers MS, Thompson JL, Vittoz N, Floresco SB, et al. Orexin A/hypocretin-1 selectively promotes motivation for positive reinforcers. J Neurosci. 2009;29:11215-11225.

27. Bentzley BS, Aston-Jones G. Orexin-1 receptor signaling increases motivation for cocaineassociated cues. Eur J Neurosci. 2015;41:1149-1156.

28. Bals-Kubik R, Ableitner A, Herz A, Shippenberg TS. Neuroanatomical sites mediating the motivational effects of opioids as mapped by the conditioned place preference paradigm in rats. J Pharmacol Exp Ther. 1993;264:489-495.

29. Ebner SR, Roitman MF, Potter DN, Rachlin AB, Chartoff EH. Depressive-like effects of the kappa opioid receptor agonist salvinorin A are associated with decreased phasic dopamine release in the nucleus accumbens. Psychopharmacology. 2010;210:241-252.

30. Robble MA, Bozsik ME, Wheeler DS, Wheeler RA. Learned avoidance requires VTA KOR-mediated reductions in dopamine. Neuropharmacology. 2020;167:107996.

31. Ramsdell CD, Meador-Woodruff JH. Expression of prodynorphin-derived peptides and mRNA in guinea-pig cortex. Neuropeptides. 1993;25:131-138.

32. Healy DJ, Meador-Woodruff JH. Prodynorphin-derived peptide expression in primate cortex and striatum. Neuropeptides. 1994;27:277-284.

33. Shippenberg TS, Chefer VI, Zapata A, Heidbreder CA. Modulation of the behavioral and neurochemical effects of psychostimulants by kappa-opioid receptor systems. Ann N Y Acad Sci. 2001;937:50-73.

34. Inutsuka A, Inui A, Tabuchi S, Tsunematsu T, Lazarus M, Yamanaka A. Concurrent and robust regulation of feeding behaviors and metabolism by orexin neurons. Neuropharmacology. 2014;85:451-460.

35. Keithley RB, Heien ML, Wightman RM. Multivariate concentration determination using principal component regression with residual analysis. Trends Analyt Chem. 2009;28:1127-1136.

36. Rosin DL, Weston MC, Sevigny CP, Stornetta RL, Guyenet PG. Hypothalamic orexin (hypocretin) neurons express vesicular glutamate transporters VGLUT1 or VGLUT2. J Comp Neurol. 2003;465:593-603.

37. Tsai H-C, Zhang F, Adamantidis A, Stuber GD, Bonci A, de Lecea L, et al. Phasic firing in dopaminergic neurons is sufficient for behavioral conditioning. Science. 2009;324:10801084.

38. Schöne C, Apergis-Schoute J, Sakurai T, Adamantidis A, Burdakov D. Coreleased orexin and glutamate evoke nonredundant spike outputs and computations in histamine neurons. Cell Rep. 2014;7:697-704. 
39. Schöne C, Cao ZFH, Apergis-Schoute J, Adamantidis A, Sakurai T, Burdakov D. Optogenetic probing of fast glutamatergic transmission from hypocretin/orexin to histamine neurons in situ. J Neurosci. 2012;32:12437-12443.

40. Borgland SL, Taha SA, Sarti F, Fields HL, Bonci A. Orexin A in the VTA is critical for the induction of synaptic plasticity and behavioral sensitization to cocaine. Neuron. 2006;49:589-601.

41. Keefer SE, Cole S, Petrovich GD. Orexin/hypocretin receptor 1 signaling mediates Pavlovian cue-food conditioning and extinction. Physiol Behav. 2016;162:27-36.

42. Narita M, Nagumo Y, Hashimoto S, Narita M, Khotib J, Miyatake M, et al. Direct involvement of orexinergic systems in the activation of the mesolimbic dopamine pathway and related behaviors induced by morphine. J Neurosci. 2006;26:398-405.

43. Chefer VI, Bäckman CM, Gigante ED, Shippenberg TS. Kappa opioid receptors on dopaminergic neurons are necessary for kappa-mediated place aversion. Neuropsychopharmacology. 2013;38:2623-2631.

44. McLaughlin JP, Marton-Popovici M, Chavkin C. $\kappa$ Opioid Receptor Antagonism and Prodynorphin Gene Disruption Block Stress-Induced Behavioral Responses. J Neurosci. 2003;23:5674-5683.

45. Margolis EB, Lock H, Chefer VI, Shippenberg TS, Hjelmstad GO, Fields HL. Kappa opioids selectively control dopaminergic neurons projecting to the prefrontal cortex. Proc Natl Acad Sci U S A. 2006;103:2938-2942.

46. Spanagel R, Herz A, Shippenberg TS. Opposing tonically active endogenous opioid systems modulate the mesolimbic dopaminergic pathway. Proc Natl Acad Sci USA. 1992;89:2046-2050.

47. Suaud-Chagny MF, Chergui K, Chouvet G, Gonon F. Relationship between dopamine release in the rat nucleus accumbens and the discharge activity of dopaminergic neurons during local in vivo application of amino acids in the ventral tegmental area. Neuroscience. 1992;49:63-72.

48. Johnson SW, Seutin V, North RA. Burst firing in dopamine neurons induced by N-methylD-aspartate: role of electrogenic sodium pump. Science. 1992;258:665-667.

49. McLaughlin JP, Land BB, Li S, Pintar JE, Chavkin C. Prior Activation of Kappa Opioid Receptors by U50,488 Mimics Repeated Forced Swim Stress to Potentiate Cocaine Place Preference Conditioning. Neuropsychopharmacology. 2006;31:787-794.

50. Ehrich JM, Phillips PEM, Chavkin C. Kappa opioid receptor activation potentiates the cocaine-induced increase in evoked dopamine release recorded in vivo in the mouse nucleus accumbens. Neuropsychopharmacology. 2014;39:3036-3048.

51. Paxinos and Franklin's the Mouse Brain in Stereotaxic Coordinates, Compact - 5th Edition. https://www.elsevier.com/books/paxinos-and-franklins-the-mouse-brain-in-stereotaxiccoordinates-compact/franklin/978-0-12-816159-3. Accessed 11 May 2020.

Figure Legends:

Figure 1. Optogenetic stimulation of $\mathbf{L H}_{\mathrm{ox} / \mathrm{dyn}}$ inputs in the VTA promotes place preference. 
A) Viral strategy schematic. Orexin-cre mice were infused with either channelrhodopsin (AAV2/8-EF1a-DIO-hChR2(H134R)-mCherry; 'ChR2') or control virus (AAV2/8-hSyn-DIOmCherry; 'mCherry'). (LH: lateral hypothalamus; VTA: ventral tegmental area)

B) Coronal brain sections (modified from [51]) representing i) estimated viral transfection areas in the $\mathrm{LH}(-1.34 \mathrm{~mm}$ in anterior-posterior plane relative to Bregma) and ii) estimated location of optical fibre implantation site in the VTA $(-3.50 \mathrm{~mm}$ in anteriorposterior plane relative to Bregma).

C) Schematic of behavioural apparatus used for all real-time place preference (RTPP) experiments. Blue square in middle panel denotes the chamber associated with $473 \mathrm{~nm}$ laser stimulation of $\mathrm{LH}_{\mathrm{ox} / \mathrm{dyn}}$. Compartments were counterbalanced across mice.

D) Immunohistochemical demonstration of fluorophore expression in LH cell bodies genetically encoded fluorophore (green; orexin-cre-eGFP) and viral transfection fluorophore (red; ChR2 mCherry); ChR2 virus infected cells were colocalized with orexin.

E) Time course of RTPP prior to and during optogenetic stimulation of $\mathrm{LH}_{\mathrm{ox} / \mathrm{dyn}}$ inputs in the VTA of mCherry (orange) or ChR2 (blue) mice in the compartment paired with stimulation (filled circles) and the no stimulation compartment (open circles). There was no significant difference in baseline percent time spent in each compartment for mCherry or ChR2 mice (mCherry: $t(7)=1.611, p=0.151 ;$ ChR2: $t(7)=0.769, p=0.467)$. Over 3 stimulation sessions of RTPP, ChR2 mice developed a significant preference for the compartment paired with $\mathrm{LH}_{\mathrm{ox} / \mathrm{d} y n}$ stimulation whereas mCherry mice did not $(3 \times 2$ repeated measures (RM) ANOVA: within subject factors: Day, $\mathrm{F}(2,14)=7.048 ; p=0.03$; Stimulation compartment, $F(1,2)=0.185, p=0.674$; between subject factor: Virus, $F(1$, 
2) $=0.3909, p=0.001 ;$ Virus $\times$ Stimulation compartment, $F(2,14)=14.493, p=0.002$;

Day $\times$ Stimulation compartment $x$ Virus, $F(2,14)=3.379, p=0.057)$; Sidak's post hoc day

$2: t(7)=3.396 ; p=0.012^{*} ;$ day $\left.3: t(7)=4.185, p=0.004^{* *}\right)$. In the post-stimulation test session, ChR2 mice preferred the compartment previously paired with stimulation, whereas mCherry mice did not (mCherry: $t(7)=0.739, p=0.484$; ChR2: $t(7)=4.603, p=$ $\left.0.002^{* *}\right)$

F) Representative heat maps of percent time spent in both compartments of the RTPP arena for mCherry and ChR2 mice on stimulation session 3.

G) Optical stimulation of $\mathrm{LH}_{\mathrm{ox} / \mathrm{dyn}}$ inputs to the VTA did not alter the distance travelled by mCherry (orange) and ChR2 (blue) mice in either the stimulation ON (filled bars) or stimulation OFF (open bars) compartments of the RTPP arena during stimulation sessions (2-way ANOVA: compartment, $\mathrm{F}(1,28)=1.434, p=0.2412$; virus, $\mathrm{F}(1,28)=$ 3.376, $p=0.0768$; virus $x$ compartment interaction, $\mathrm{F}(1,28)=0.2695, p=0.6077)$.

H) Optical stimulation of $\mathrm{LH}_{\mathrm{ox} / \mathrm{dyn}}$ inputs to the VTA did not alter velocity of locomotor activity mCherry (orange) and ChR2 (blue) mice in either the stimulation ON (filled bars) or stimulation OFF (open bars) compartments during stimulation sessions (2-way ANOVA: compartment, $\mathrm{F}(1,28)=0.5144, p=0.4792 ;$ virus, $\mathrm{F}(1,28)=6.391, p=0.0174$ chamber $x$ virus interaction: $F(1,28)=0.1991, p=0.6589)$.

Figure 2. OxR1 mediates preference induced by optogenetic stimulation of $\mathbf{L H}_{\mathrm{ox} / \mathrm{dyn}}$ inputs in the VTA. 
A) All mice did not show a significant preference for either compartment prior to stimulation sessions (vehicle: $t(4)=0.562, p=0.604$; SB-334867: $t(4)=0.543, p=0.616$ ). Over 3 stimulation sessions of RTPP, ChR2 mice receiving vehicle injections (blue) developed a preference for the chamber paired with $\mathrm{LH}_{\mathrm{ox} / \mathrm{dyn}}$ stimulation (filled circles) in the VTA, whereas ChR2 mice receiving SB-334867 injections (pink) did not develop a preference for the stimulation ON compartment (filled circles) or the stimulation OFF compartment (open circles) of the RTPP arena (Vehicle 2-way RM ANOVA: day: $F(4,20)=$ 4.848, $p=0.0067$; compartment: $\mathrm{F}(1,20)=59.51, p<0.0001$; day $\times$ compartment interaction: $F(4,20)=3.857, p=0.0176$; SB-334867 2-way RM ANOVA: 2-way RM ANOVA: day: $\mathrm{F}(4,20)=0.6629, p=0.625$, compartment: $\mathrm{F}(1,20)=0.003850, p=0.9511$ day $\mathrm{x}$ compartment interaction: $\mathrm{F}(4,20)=0.2313, p=0.9175)$. A Sidak's multiple comparison test revealed significant differences in stimulation on days $1\left(p=0.0160^{*}\right), 2$ $(p$ $=\left(0.0058^{* *}\right)$, and

$(p<0.0001)$ in the vehicle treated group. ChR2 mice receiving vehicle injections (blue) also demonstrated a preference for the stimulation ON chamber (filled circles) during the post stimulation test session, whereas ChR2 mice receiving SB-334867 (pink) did not (vehicle: $t(4)=4.071, p=0.002^{* *} ;$ SB-334867: $t(4)=0.160, p=0.881$ ).

B) Representative heat maps of the percent time spent on day 3 of stimulation sessions in both compartments of the RTPP arena by ChR2 mice receiving either vehicle (left) or SB334867 (right) injections prior to each stimulation session.

C) Distance travelled of ChR2 mice was reduced in mice administered SB-334867 (pink) compared to vehicle (blue) averaged over the 3 stimulation sessions. However, there 
was no difference in distance travelled in compartments with intra-VTA $\mathrm{LH}_{\mathrm{ox} / \mathrm{dyn}}$ stimulation ON (filled bars) compared to stimulation OFF (open bars; 2-way ANOVA: Drug, $F(1,8)=8.572, p=0.0191 ;$ Compartment, $F(1,8)=1.112, p=0.2171 ;$ drug $x$ compartment interaction, $\mathrm{F}(1,8)=0.2988, p=0.5996)$

D) Velocity of ChR2 mice was reduced in mice administered SB-334867 (pink) compared to vehicle (blue) averaged over the 3 stimulation sessions. However, there was no difference in velocity in compartments with intra-VTA $\mathrm{LH}_{\mathrm{ox} / \mathrm{dyn}}$ stimulation ON (filled bars) compared to stimulation OFF (open bars: 2-way ANOVA: Drug, $F(1,8)=5.672, p=$ 0.0444; Compartment, $\mathrm{F}(1,8)=3.156, p=0.1136$, Drug $\times$ Compartment interaction, $\mathrm{F}(1,8)=3.787, p=0.0875)$.

E) All mice did not show a significant preference for either compartment prior to stimulation sessions (vehicle: $t(6)=0.571, p=0.5887$; norBNI: $t(4)=1.605, p=0.1837$ ). Over 3 stimulation sessions of RTPP, ChR2 mice receiving vehicle injections (blue) or norBNI injections (pink) developed a preference for the chamber paired with $\mathrm{LH}_{\mathrm{ox} / \mathrm{dyn}}$ stimulation (filled circles) in the VTA, (Vehicle 2-way RM ANOVA: day: $F(1.901,22.81)=$ $0.00, p>0.99$; compartment: $\mathrm{F}(1,12)=32.37, p<0.0001$; day $\mathrm{x}$ compartment interaction: $\mathrm{F}(4,48)=8.281, p<0.0001$; norBNI, 2-way RM ANOVA: 2-way RM ANOVA: day: $F(1.842,14.74)=0.0004, p>0.99$, compartment: $F(1,8)=32.51, p=0.0005$, day $x$ compartment interaction: $F(4,32)=5.642, p=0.0015$. Sidak's multiple comparisons tests revealed significant differences on days $1(p=0.0043)^{* *}, 2(p<0.0001)^{* * * *}$, and $3(p=$ $0.0218)^{*}$ in the vehicle group and on days $2(p=0.0151)^{*}$, and $3(p=0.0030)^{* *}$ in the norBNI group. ChR2 mice receiving vehicle injections (blue) also demonstrated a 
preference for the stimulation ON chamber (filled circles) during the post stimulation test session, whereas ChR2 mice receiving norBNI (pink) did not (vehicle: $t(6)=2.656, p$ $=0.0377^{*} ;$ norBNI: $\left.t(4)=0.144, p=0.222\right)$.

F) Representative heat maps of the percent time spent on day 3 of stimulation sessions in both compartments of the RTPP arena by ChR2 mice receiving either vehicle (left) or norBNI (right) injections prior to each stimulation session.

G) Distance travelled of ChR2 mice was not different in mice administered norBNI (pink) compared to vehicle (blue) averaged over the 3 stimulation sessions in compartments with intra-VTA $\mathrm{LH}_{\mathrm{ox} / \mathrm{dyn}}$ stimulation ON (filled bars) compared to stimulation OFF (open bars; 2-way ANOVA: Drug, $\mathrm{F}(1,20)=0.8194, p=0.3761 ;$ Compartment, $\mathrm{F}(1,20)=1.844, p$ $=0.1896 ;$ drug $\times$ compartment interaction, $F(1,20)=0.1420, p=0.7103)$

H) Velocity of ChR2 mice was reduced in mice administered norBNI (pink) compared to vehicle (blue) averaged over the 3 stimulation sessions. However, there was no difference in velocity in compartments with intra-VTA $\mathrm{LH}_{\mathrm{ox} / \mathrm{dyn}}$ stimulation ON (filled bars) compared to stimulation OFF (open bars: 2-way ANOVA: Drug, $F(1,20)=7.618, p=$ 0.0121; Compartment, $\mathrm{F}(1,20)=2.466, p=0.1320$, Drug $\times$ Compartment interaction, $\mathrm{F}(1,20)=0.4917, p=0.4912)$.

Figure 3. Optogenetic stimulation of $\mathbf{L H}_{\mathrm{ox} / \mathrm{dyn}}$ inputs in the VTA potentiates evoked NAC dopamine release. 
A) Schematic of viral injection (LH), electrode and optical fibre placement and stimulation parameters (VTA), and fast-scan cyclic voltammetry (FSCV) recording location in the NAC core.

B) Coronal brain sections (modified from [51]) at 6 different anterior-posterior locations relative to Bregma illustrating the approximate recording (top; pink circles) and stimulating (bottom; blue squares) locations of FSCV data. Approximate electrode tip location was retrospectively determined using the electrode track and recording depths (relative to brain surface).

C) Averaged dopamine traces for mCherry (top left, orange) and ChR2 (top right, blue) groups in response to electrical stimulation. Representative false colour plots of dopamine concentration for mCherry (bottom left) and ChR2 (bottom right) mice following electrical stimulation. In all panels, grey box denotes $60 \mathrm{~Hz}$ 60pulses (1s) electrical stimulation onset and offset. Inset to colour plots, current-voltage plot showing oxidation and reduction peaks for dopamine. Inset, current-voltage plot showing oxidation and reduction peaks for dopamine.

D) Averaged dopamine traces for mCherry (top left, orange) and ChR2 (top right, blue) groups in response to laser stimulation. Representative false colour plots of dopamine concentration for mCherry (bottom left) and ChR2 (bottom right) mice following electrical stimulation. In all panels blue box denotes optical stimulation $(2 \mathrm{~Hz})$ onset and offset. Inset, current-voltage plot showing oxidation and reduction peaks for dopamine.

E) Averaged dopamine traces for mCherry (top left, orange) and ChR2 (top right, blue) groups in response to electrical and laser stimulation. Representative false colour plots 
of dopamine concentration for mCherry (bottom left) and ChR2 (bottom right) mice following electrical and optical stimulation. In all panels blue box denotes optical stimulation $(20 \mathrm{~Hz})$ and electrical stimulation $(60 \mathrm{~Hz})$ onset and offset.

F) There was no significant difference in the peak dopamine concentration ([DA]) recorded for electrical and electrical (open bars) and laser (filled bars) stimulation for mCherry mice (orange; 2 -way ANOVA: virus $(F(1,13)=36.198, p=0.0032$; stimulation: $F(1,13)=$ 4.808, $p=0.033$; virus $\times$ stimulation interaction: $F(1,13)=10.390, p=0.047)$. However, ChR2 mice (blue) showed significantly greater peak dopamine in response to electrical and laser stimulation (filled bars) compared to electrical stimulation alone (open bars; Sidak's post hoc: mCherry, $p=0.1812 ;$ ChR2, $\left.p=0.0001^{* * *}\right)$.

G) There was no significant difference in the AUC for dopamine concentration in response to electrical (open bars) and electrical and laser stimulation (filled) for mCherry mice (orange; 2-way RM ANOVA: virus, $F(1,13)=7.795, p=0.0153$, optical stimulation, $F(1,13)=4.48, p=0.0473$; virus $\times$ stimulation interaction: $F(1,13)=10.38, p=0.0067)$. ChR2 (blue) showed a significant potentiation of dopamine AUC in response to electrical and laser stimulation (filled bars) compared to electrical stimulation alone (open bars; Sidak's post hoc: $\mathrm{mCherry,} p=0.5391 ;$ ChR2, $\left.p=0.001^{* *}\right)$.

Figure 4. OxR1 is required for potentiation of evoked NAc dopamine release by optogenetic stimulation of $\mathrm{LH}_{\mathrm{ox} / \mathrm{dyn}}$ inputs in the VTA.

A) Averaged dopamine traces and representative false colour plots in response to electrical stimulation (top) and electrical and laser stimulation (bottom) for mCherry mice before 
(green) and after administration of SB-334867 (magenta). Insets to colour plots, current voltage plots showing oxidation and reduction peaks for dopamine.

B) Averaged dopamine traces and representative false colour plots in response to electrical stimulation (top) and electrical and laser stimulation (bottom) for ChR2 mice before (green) and after administration of SB-334867 (magenta). Insets to colour plots, current voltage plots showing oxidation and reduction peaks for dopamine.

C) (i) Prior to administration of SB-334867, there was no significant difference in the peak dopamine concentration observed in response to electrical (open bars) or electrical and laser stimulation (filled bars) for mCherry mice (orange). For ChR2 mice (blue), laser stimulation (filled bars) significantly potentiated the peak dopamine concentration observed in response to electrical stimulation (open bars; 2-way RM ANOVA: stimulation, $\mathrm{F}(1,12)=18.28, p=0.0011$; virus: $\mathrm{F}(1,12)=0.27983, p=0.3892$, stimulation $x$ virus interaction: $F(1,12)=22.09, p=0.0005)$. A Sidak's post hoc test indicated $a$ significant difference in peak evoked dopamine in ChR2 $\left(p<0.0001^{* * * *}\right)$, but not mCherry mice ( $p=0.9469$ ). (ii) After administration of SB-334867, there was no significant difference in the peak dopamine concentration observed in response to electrical (open bars) or electrical and laser stimulation (filled bars) for mCherry (orange) or ChR2 mice (blue; 2-way RM ANOVA: stimulation, $\mathrm{F}(1,12)=0.7 .881, p=0.0 .158$; virus, $\mathrm{F}(1,12)=2.748, p=0.1233$, stimulation $\mathrm{x}$ virus interaction: $\mathrm{F}(1,12)=2.748, p=0.1233)$.

D) (i) Prior to administration of SB-334867, there was no significant difference in the AUC of evoked dopamine observed in response to electrical (open bars) or electrical and laser stimulation (filled bars) for mCherry mice (orange). For ChR2 mice (blue), laser 
stimulation (filled bars) significantly potentiated the AUC observed in response to electrical stimulation (open bars; 2-way RM ANOVA: stimulation, $F(1,12)=11.73, p=$ 0.0050 ; virus: $F(1,12)=3.574, p=0.0831$; stimulation $x$ virus interaction: $F(1,12)=16.64$, $p=0.0015$. A Sidak's post hoc test indicated a significant difference in peak evoked dopamine in ChR2 $\left(p=0.0004^{* * *}\right)$, but not mCherry mice $(p=0.8784)$. (ii) After administration of SB-334867, there was no significant difference in the peak dopamine concentration observed in response to electrical (open bars) or electrical and laser stimulation (filled bars) for mCherry (orange) or ChR2 mice (blue; 2-way RM ANOVA: stimulation, $\mathrm{F}(1,12)=1.154, p=0.3039 ;$ virus, $\mathrm{F}(1,12)=2.392, p=0.1479$, stimulation $\mathrm{x}$ virus interaction: $\mathrm{F}(1,12)=0.2155, p=0.6508)$.

E) (i) Prior to administration of norBNI, there was no significant difference in the peak dopamine concentration observed in response to electrical (open bars) or electrical and laser stimulation (filled bars) for mCherry mice (orange). For ChR2 mice (blue), laser stimulation (filled bars) significantly potentiated the peak dopamine concentration observed in response to electrical stimulation (open bars; 2-way RM ANOVA: stimulation, $\mathrm{F}(1,9)=4.755, p=0.0571$; virus: $\mathrm{F}(1,9)=0.5213, p=0.4886$, stimulation $\mathrm{x}$ virus interaction: $F(1,9)=5.919, p=0.0378)$. A Sidak's post hoc test indicated a significant difference in peak evoked dopamine in ChR2 $\left(p=0.0244^{*}\right)$, but not mCherry mice $(p=0.9792)$. (ii) After administration of norBNI, there was a significant difference in the peak dopamine concentration observed in response to electrical (open bars) or electrical and laser stimulation (filled bars) for mCherry (orange) or ChR2 mice (blue; 2way RM ANOVA: stimulation, $F(1,9)=5.655, p=0.0414$; virus, $F(1,9)=1.199, p=0.3019$, 
stimulation $x$ virus interaction: $F(1,9)=5.357, p=0.0459)$. A Sidak's post hoc test indicated a significant difference in peak evoked dopamine in ChR2 $\left(p=0.0224^{*}\right)$, but not mCherry mice $(p=0.9987)$.

F) (i) Prior to administration of norBNI, there was no significant difference in the AUC of evoked dopamine observed in response to electrical (open bars) or electrical and laser stimulation (filled bars) for mCherry mice (orange) or for ChR2 mice (blue) (2-way RM ANOVA: stimulation, $F(1,9)=3.03, p=0.1150 ;$ virus: $F(1,9)=1.057, p=0.3308$; stimulation $x$ virus interaction: $F(1,9)=3.773, p=0.084$. Given that peak dopamine concentration before norBNI was significantly different after laser stimulation in ChR2, we made the a priori hypothesis that it would also be different for AUC. However, a Sidak's post hoc test indicated no significant differences in peak evoked dopamine in ChR2 ( $p=0.067)$ or mCherry mice $(p=0.9871)$. (ii) After administration of norBNI, there was no significant difference in the peak dopamine concentration observed in response to electrical (open bars) or electrical and laser stimulation (filled bars) for mCherry (orange) or ChR2 mice (blue; 2-way RM ANOVA: stimulation, $\mathrm{F}(1,9)=3.460, p=0.0770$; virus, $F(1,9)=1.822, p=0.2088$, stimulation $x$ virus interaction: $F(1,9)=3.460, p=$ 0.0958). Given that peak dopamine concentration after norBNI was significantly different after laser stimulation in ChR2, we made the a priori hypothesis that it would also be different for AUC. However, a Sidak's post hoc test indicated no significant differences in peak evoked dopamine in ChR2 $(p=0.0557)$ or mCherry mice $(p=0.9939)$. 
Figure 5. Optogenetic stimulation of $\mathrm{LH}_{\mathrm{ox} / \mathrm{dyn}}$ inputs to VTA neurons can potentiate NMDA currents.

A) Time course of electrically evoked NMDA ESPCS of VTA dopamine neurons before and after $20 \mathrm{~Hz}, 10 \mathrm{~s}$ optical stimulation (green line) of $\mathrm{LH}_{\mathrm{ox} / \mathrm{dyn}}$ inputs.

B) Bar graph of averages and individual evoked NMDA responses before (open) and 5 min after (filled) optical stimulation of $\mathrm{LH}_{\mathrm{ox} / \mathrm{dyn}}$ inputs to VTA dopamine neuron. Wilcoxon matched-pairs signed rank test, $p=0.0122^{*}, \mathrm{~W}=62, \mathrm{~N} / \mathrm{n}=12 / 6$.

C) Example traces evoked at $+40 \mathrm{mV}$ before (black) and after (blue) optical stimulation of $\mathrm{LH}_{\mathrm{ox} / \mathrm{dyn}}$ inputs to VTA dopamine neurons.

D) Time course of electrically evoked NMDA ESPCS of VTA dopamine neurons before and after $20 \mathrm{~Hz}, 10 \mathrm{~s}$ optical stimulation (green line) of $\mathrm{LH}_{\mathrm{ox} / \mathrm{dyn}}$ inputs in the presence of SB$334867(1 \mu \mathrm{M})$ and norBNI $(1 \mu \mathrm{M})$ throughout the experiment.

E) Bar graph of averages and individual evoked NMDA responses before (open) and 5 min after (filled) optical stimulation of $\mathrm{LH}_{\mathrm{ox} / \mathrm{dyn}}$ inputs to VTA dopamine neuron in the presence of SB-334867 (1 $\mu \mathrm{M})$ and norBNI $(1 \mu \mathrm{M})$. Wilcoxon matched-pairs signed rank test, $p=0.00078^{* *}, \mathrm{~W}=-36, \mathrm{~N} / \mathrm{n}=8 / 4$.

F) Example traces evoked at $+40 \mathrm{mV}$ before (black) and after (blue) optical stimulation of $\mathrm{LH}_{\mathrm{ox} / \mathrm{dyn}}$ inputs to VTA dopamine neurons in the presence of SB-334867 (1 $\left.\mu \mathrm{M}\right)$ and norBNI $(1 \mu \mathrm{M})$. 
bioRxiv preprint doi: https://doi.org/10.1101/2020.09.10.291963; this version posted June 11, 2021. The copyright holder for this preprint (which was not certified by peer review) is the author/funder, who has granted bioRxiv a license to display the preprint in perpetuity. It is made available under aCC-BY-NC-ND 4.0 International license. 
bioRxiv preprint doi: https://doi.org/10.1101/2020.09.10.291963; this version posted June 11, 2021. The copyright holder for this preprint (which was not certified by peer review) is the author/funder, who has granted bioRxiv a license to display the preprint in perpetuity. It is made available und raec-BY-NC-ND 4.0 international license.

A

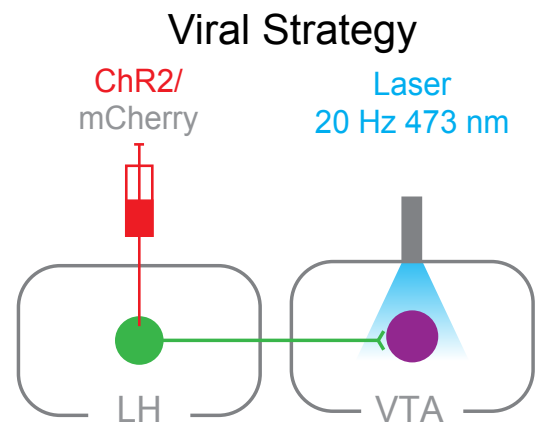

C

$\mathrm{E}$

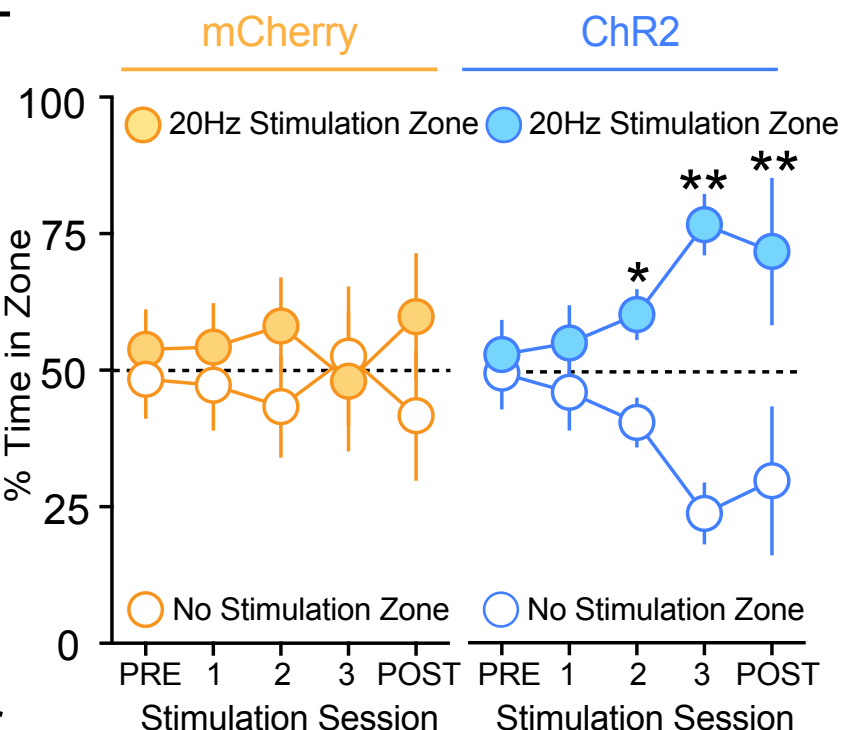

G

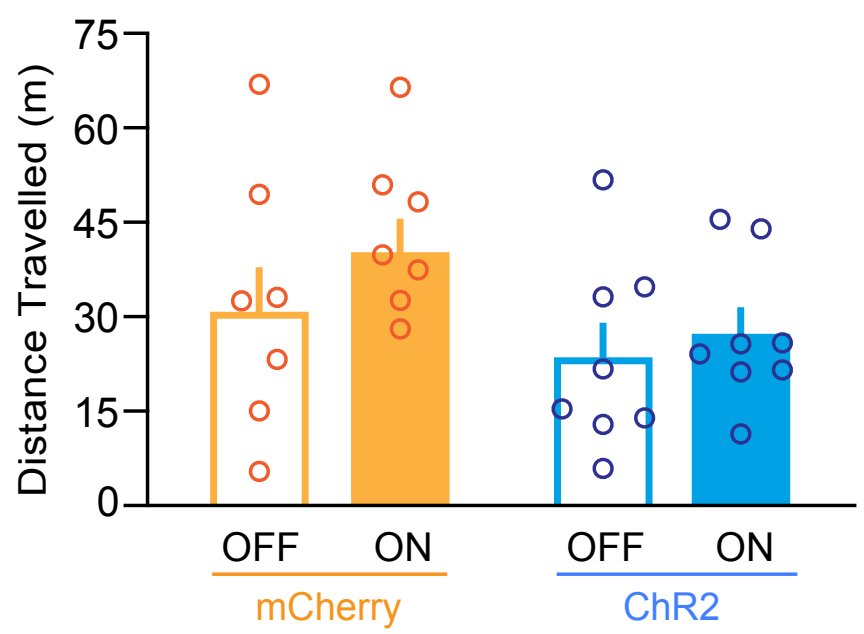

B Viral Injection and Fiber Placement

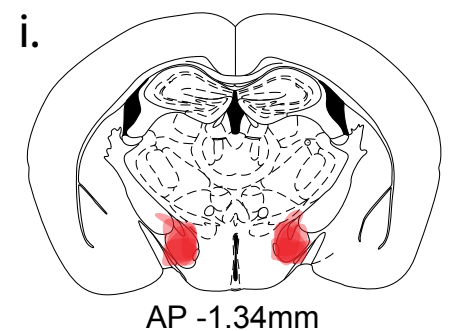

ii.

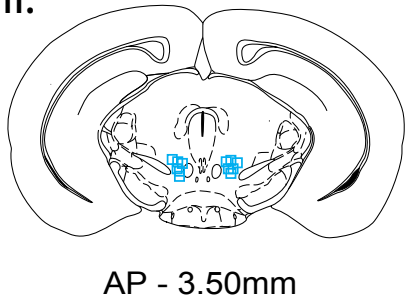

$\mathrm{D}$

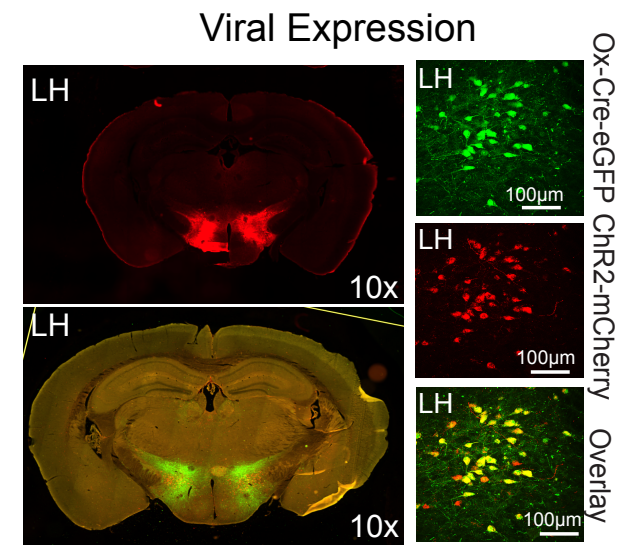

$\mathrm{F}$

mCherry

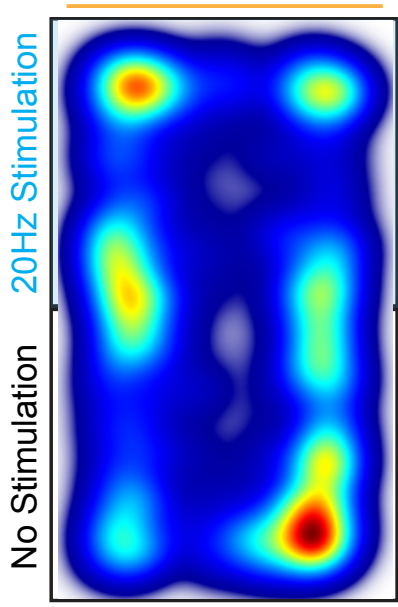

Day 3

$\mathrm{H}$

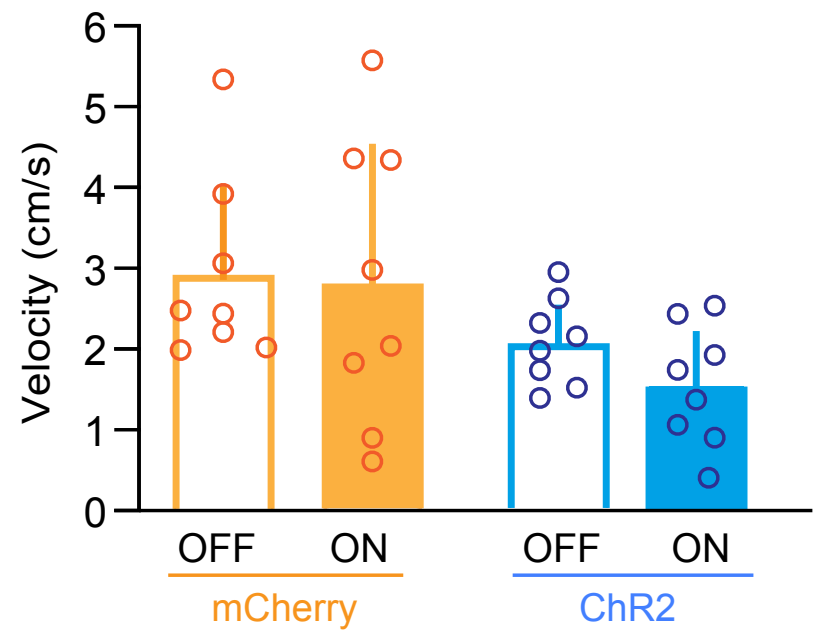


bioRxiv preprint doi: https://doi.org/10.1101/2020.09.10.291963; this version posted June 11, 2021. The copyright holder for this preprint

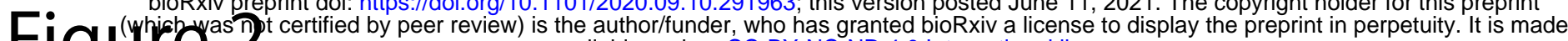

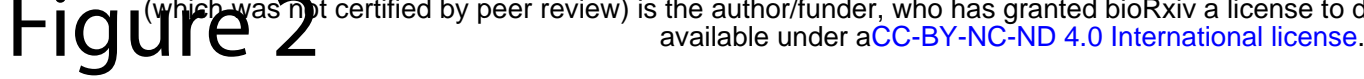

A

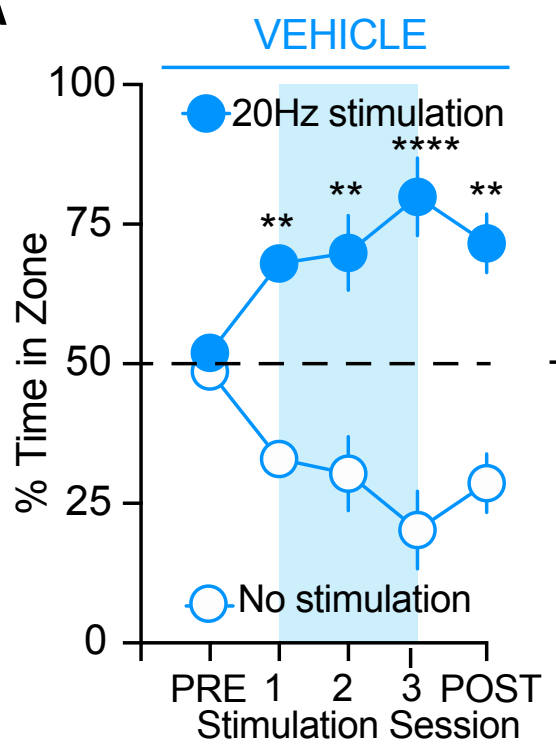

B

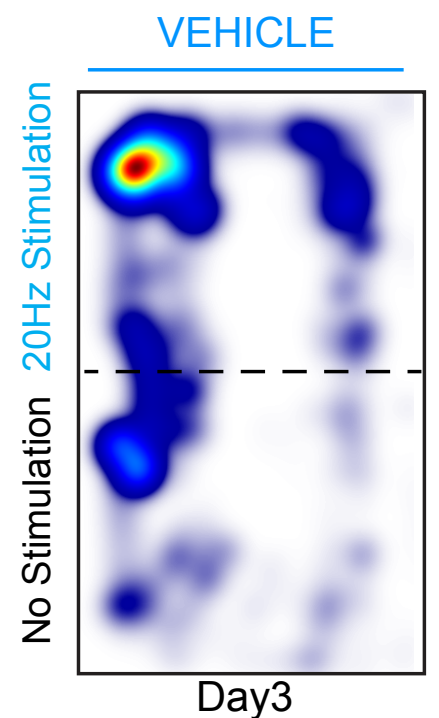

C
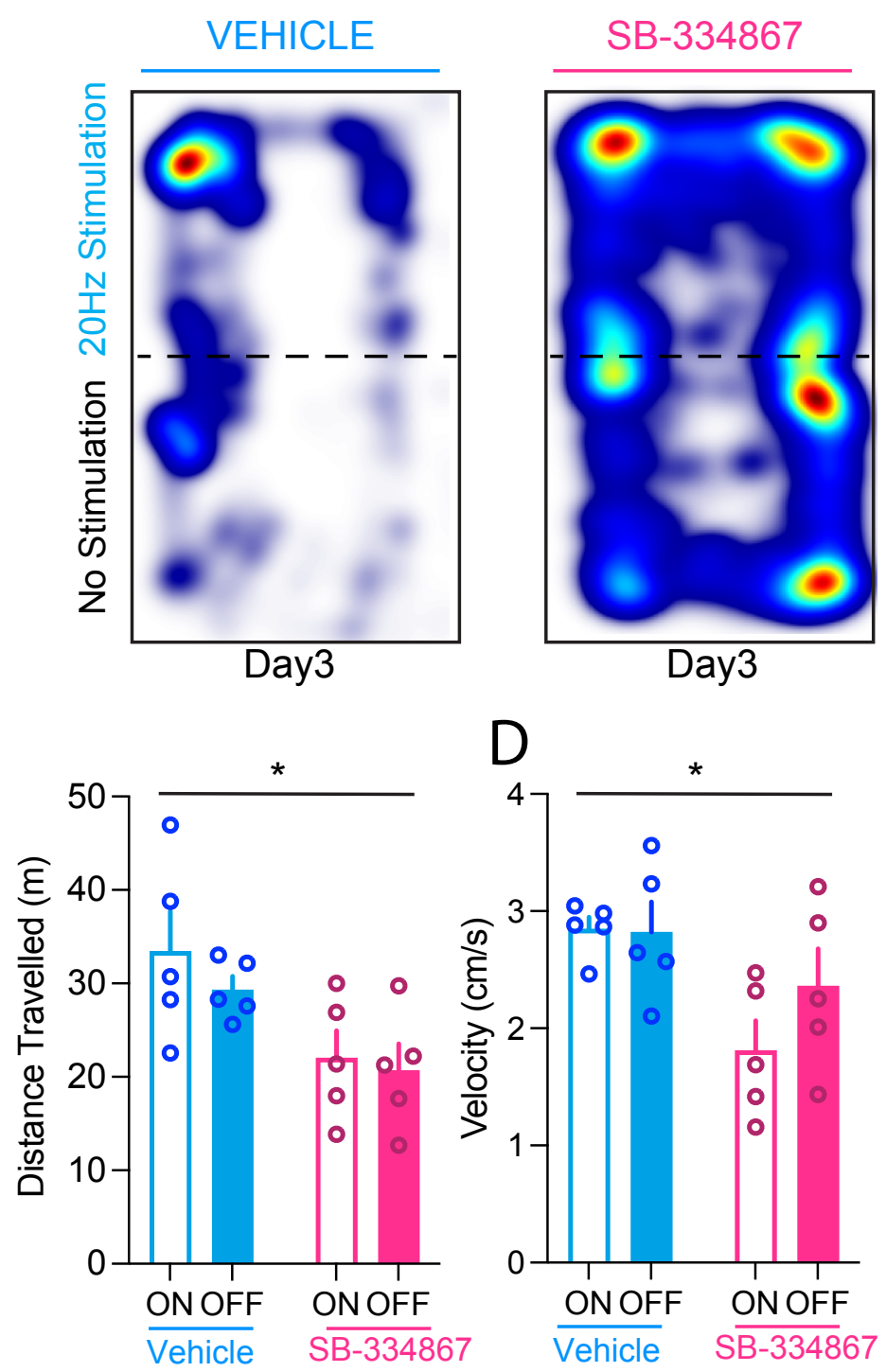

Day3
E

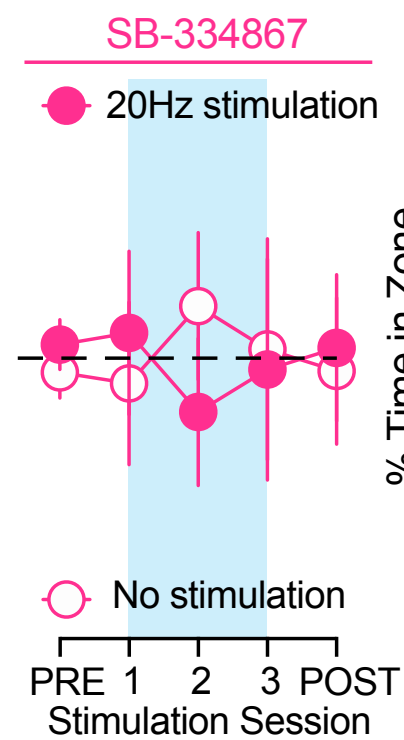

$\mathrm{F}$

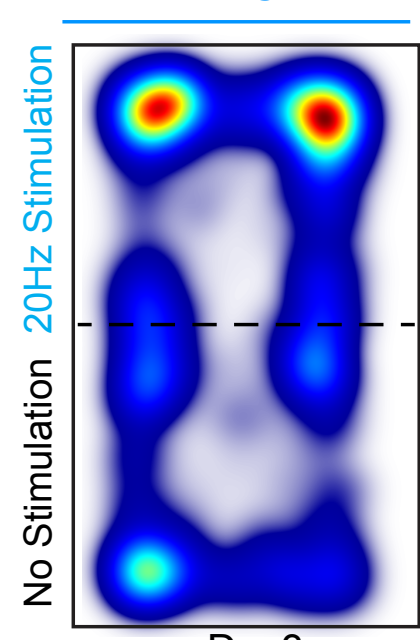

Day3

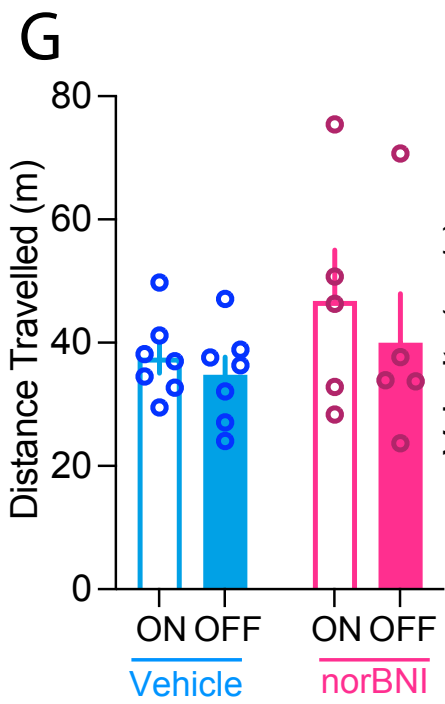

$\mathrm{H}$

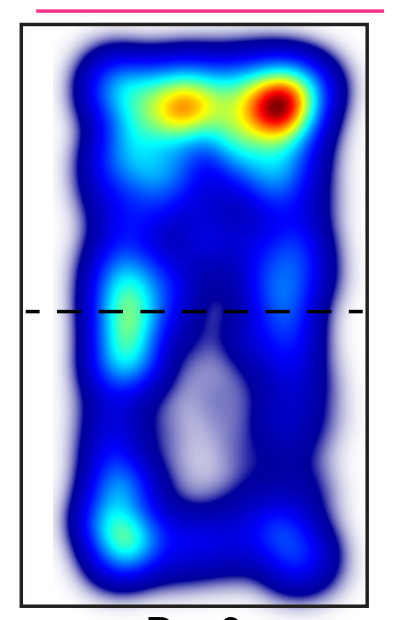

Day3

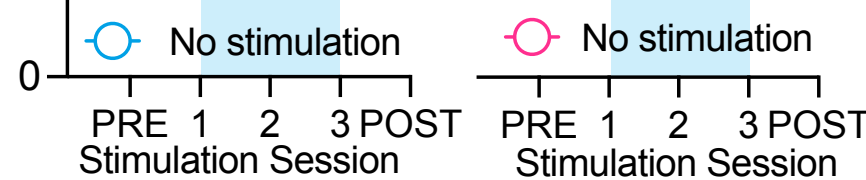

Stimulation Session

norBN

$20 \mathrm{~Hz}$ stimulation

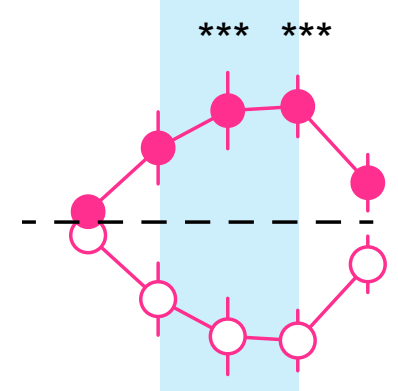

F

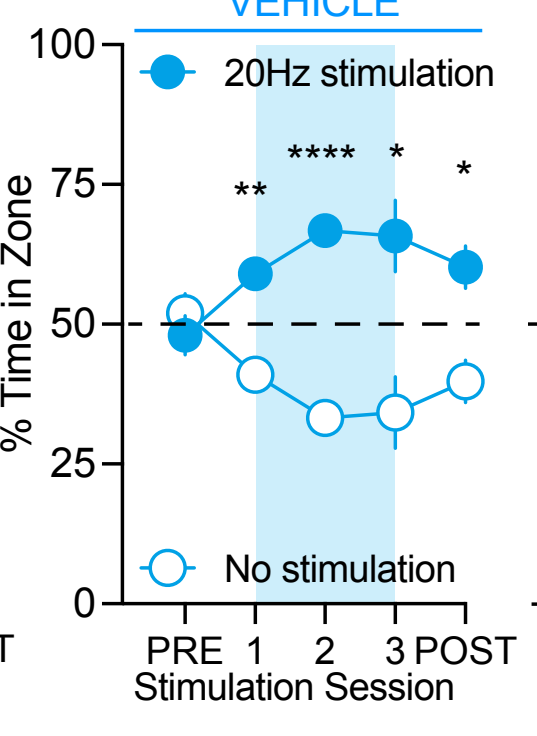

norBNI

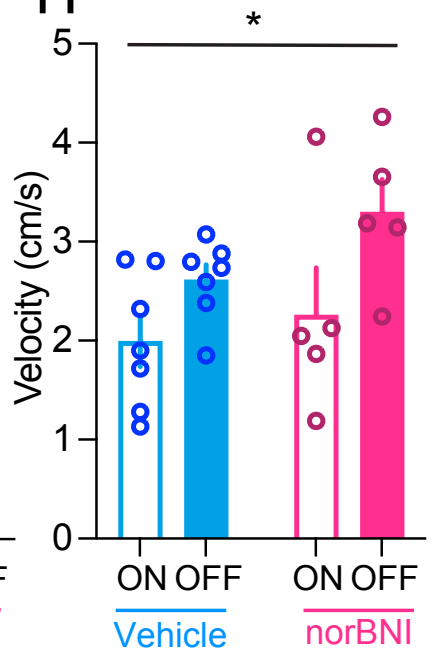


bioRxiv preprint doi: https://doi.org/10.1101/2020.09.10.291963; this version posted June 11, 2021. The copyright holder for this preprint (which was not certified by peer review) is the author/funder, who has grant bioRxiv a license to display the preprint in perpetuity. It is made

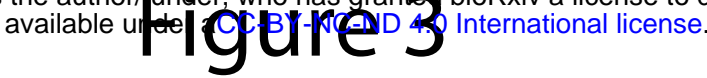
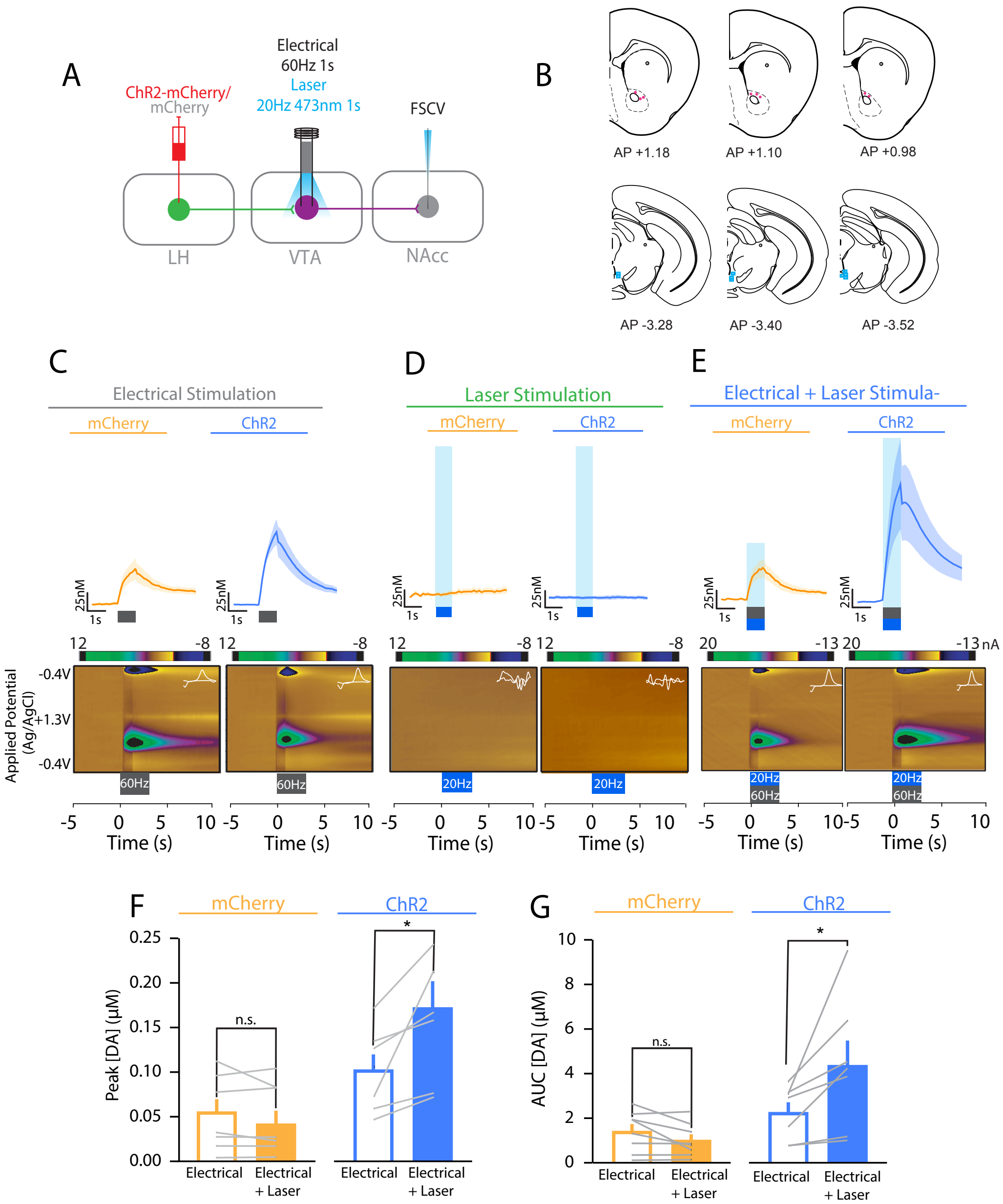
bioRxiv preprint doi: https://doi.org/10.1101/2020.09.10201963; this version pgsted June 11, 2021. The copyright holder for this preprint

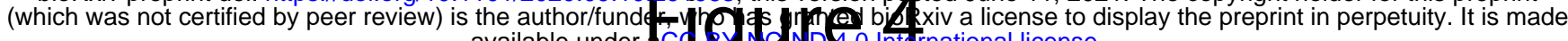

A mCherry

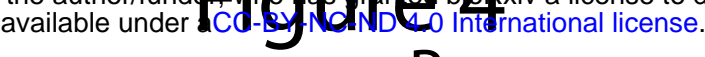

Electrical Stimulation Electrical + Laser Stimulation

B

ChR2
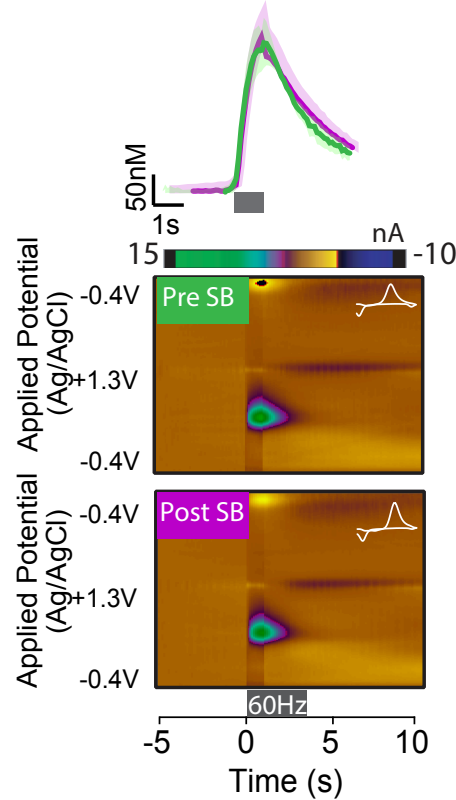

C PRE SB-334867

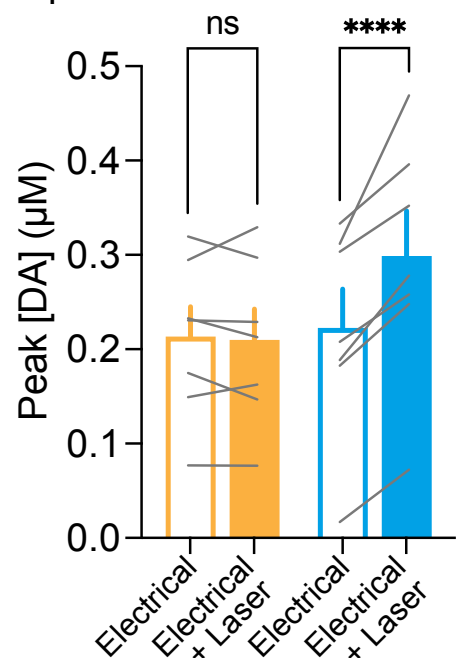

E
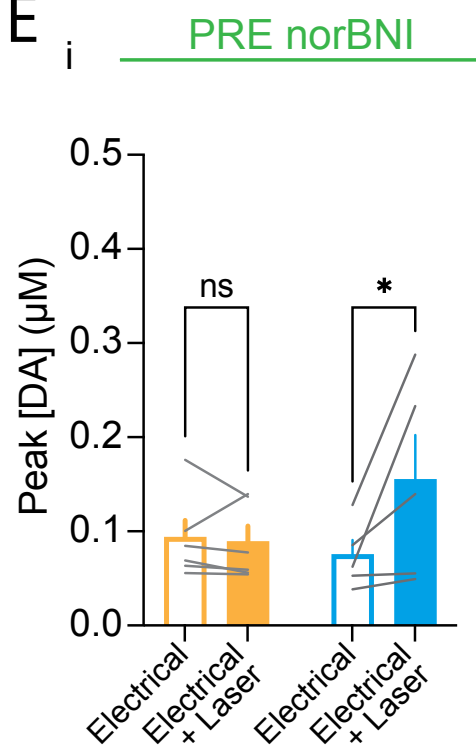

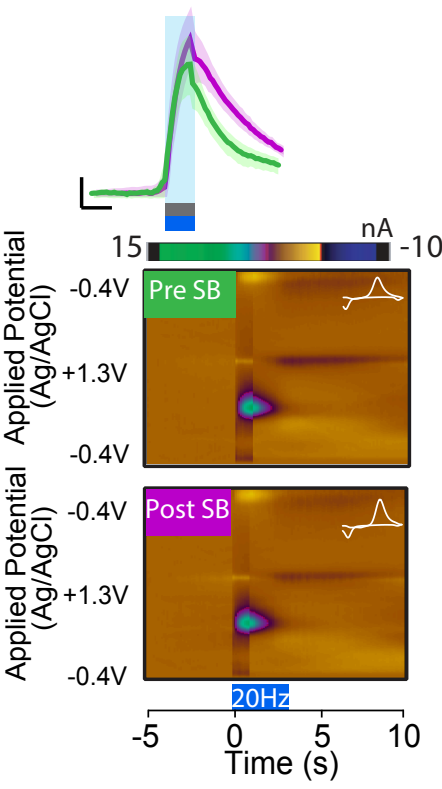

POST SB-334867
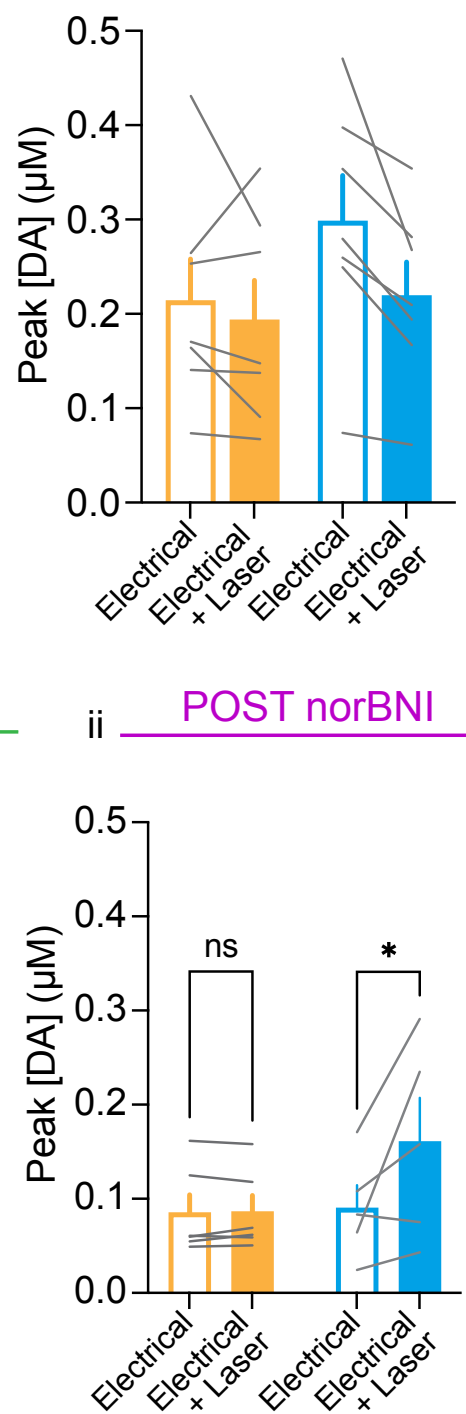

Electrical Stimulation Electrical + Laser Stimulation
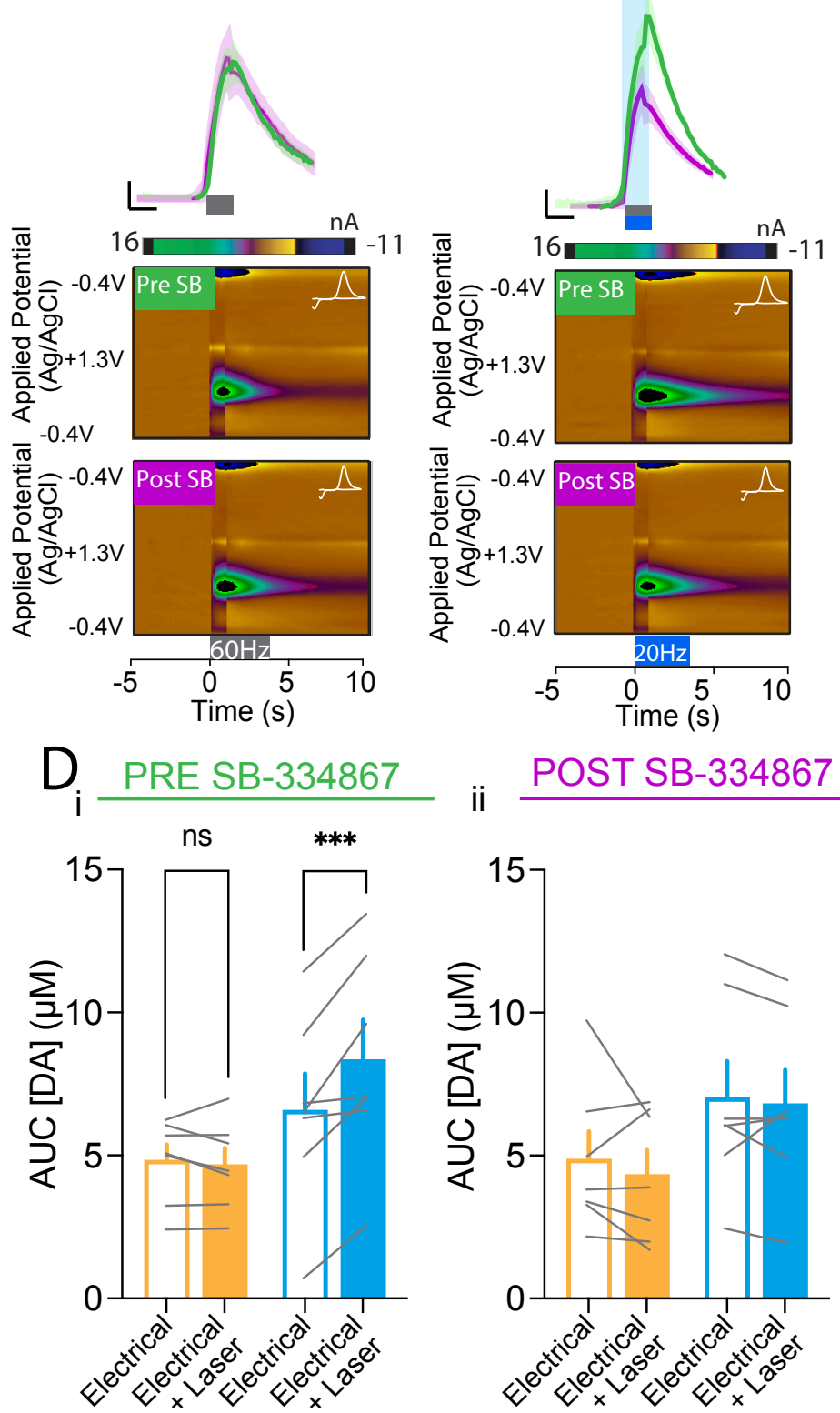

$F_{i}$
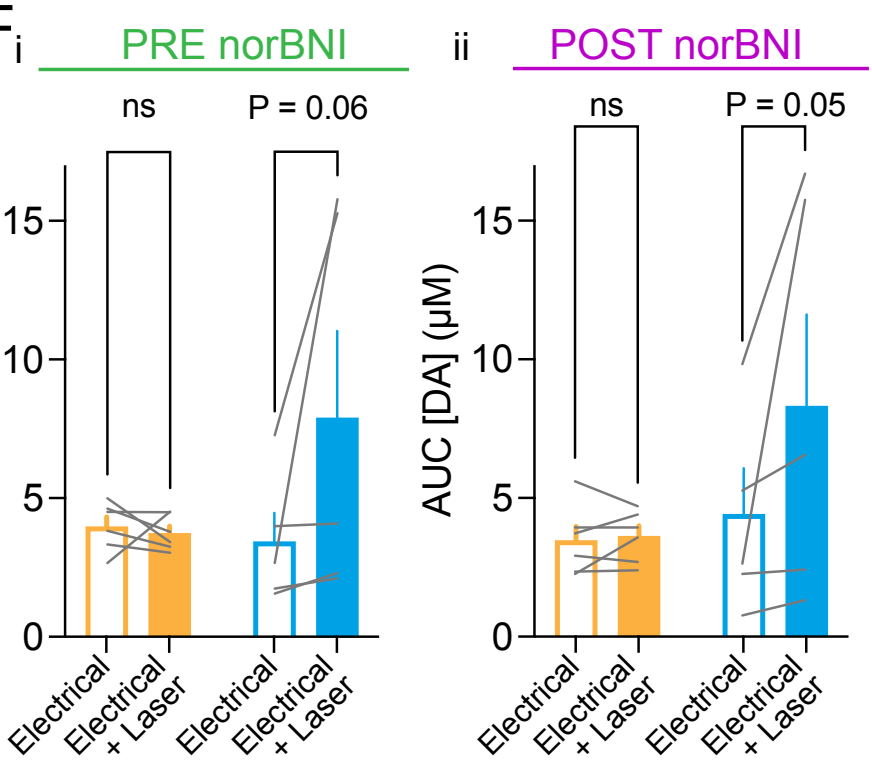
bioRxiv preprint doi: https://doi org/10.1101/2020.09.10.291963; this version posted June 11, 2021. The copyright holder for this preprint (which was not certified by peer review) is the author/fumder, who has grant bioRxiv a license to display the preprint in perpetuity. It is made

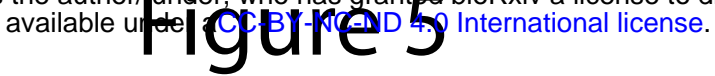

A

B

Laser Stimulation
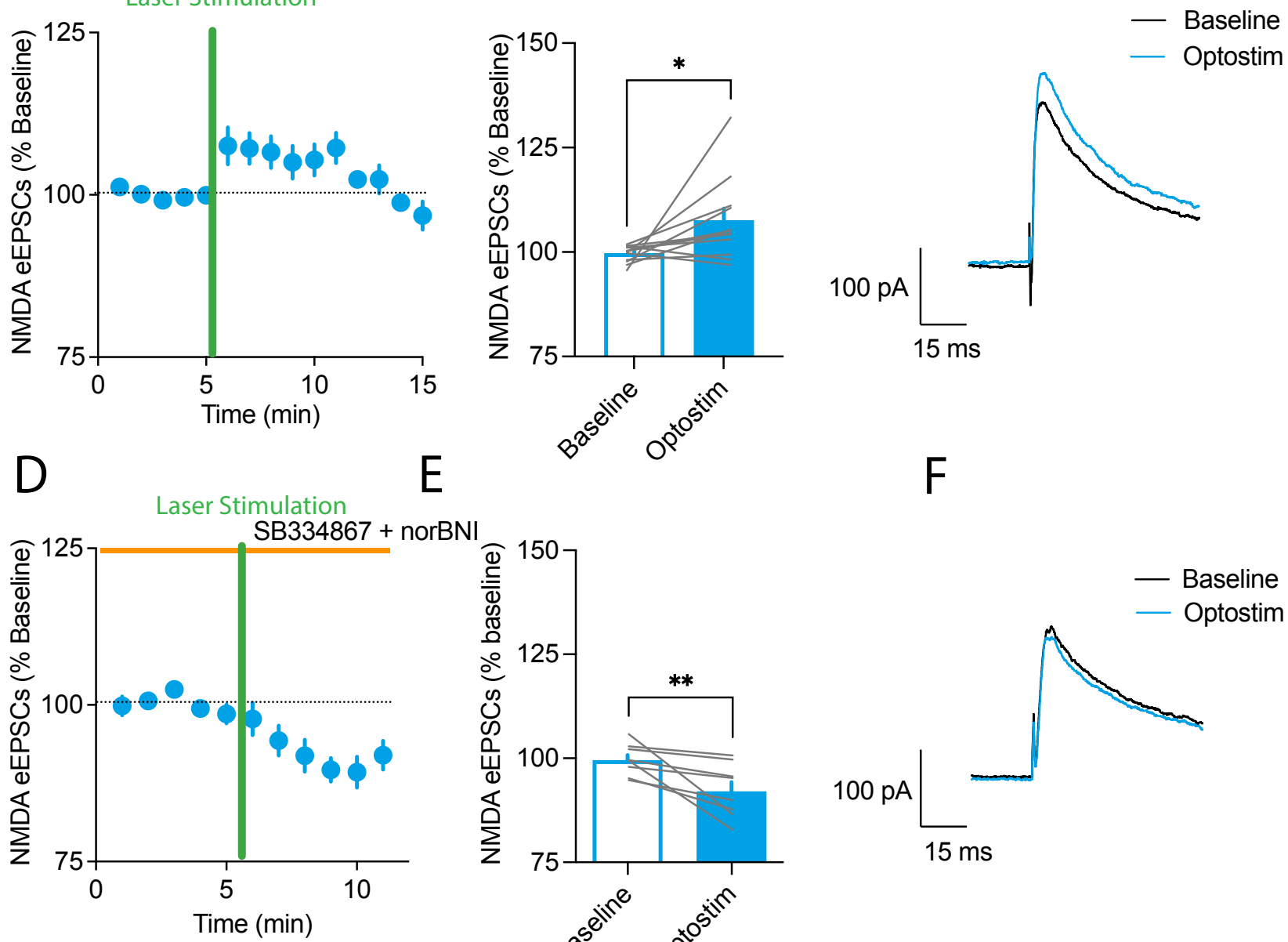

$\mathrm{E}$

$\mathrm{F}$
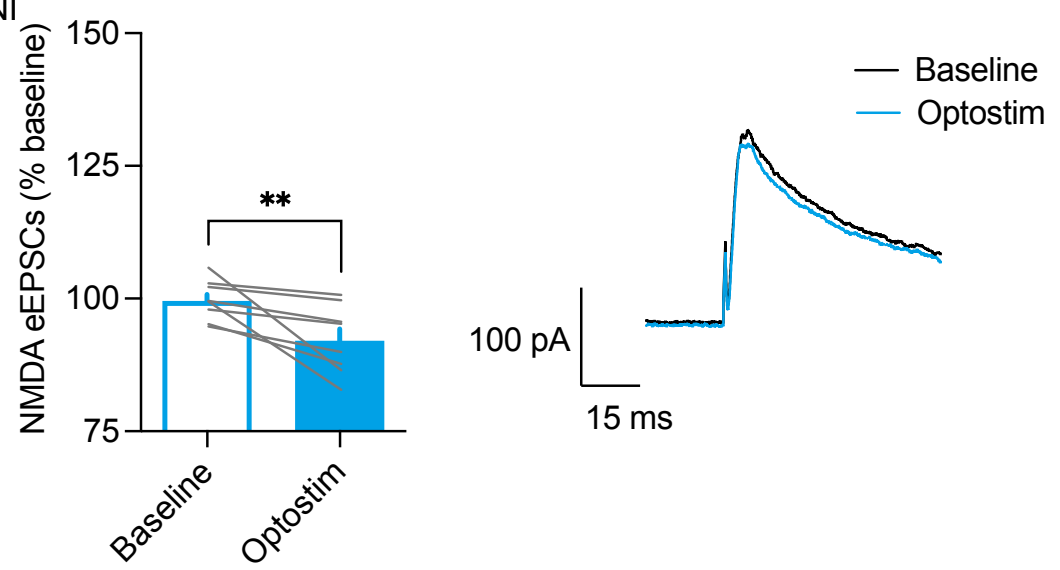
bioRxiv preprint doi: https://doi.org/10.1101/2020.09.10.291963; this version posted June 11, 2021. The copyright holder for this preprint (which was not certified by peer review) is the author/funder, who has granted bioRxiv a license to display the preprint in perpetuity. It is made available under aCC-BY-NC-ND 4.0 International license.

A
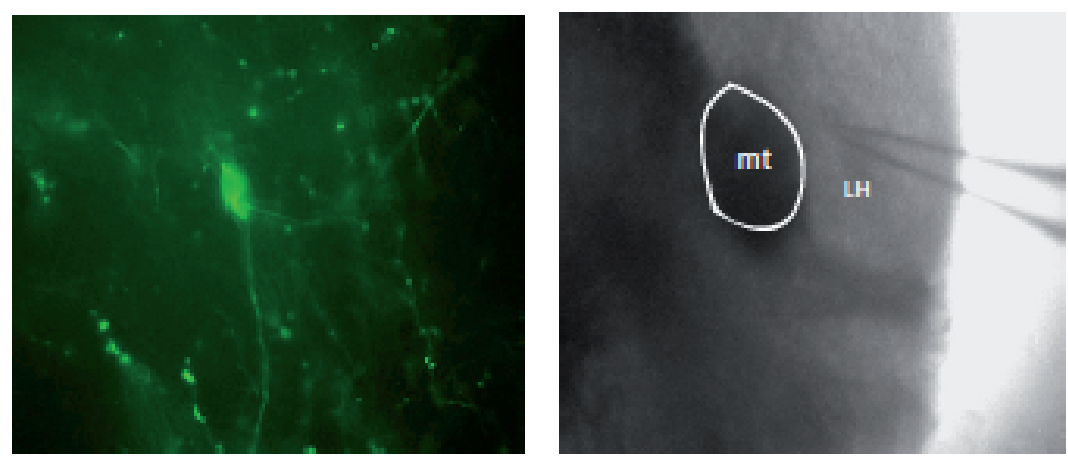

B ChR2-0 to $100 \mathrm{~ms}$ in $10 \mathrm{~ms}$ increments

Optically evoked firing in LHox/dyn neurons D
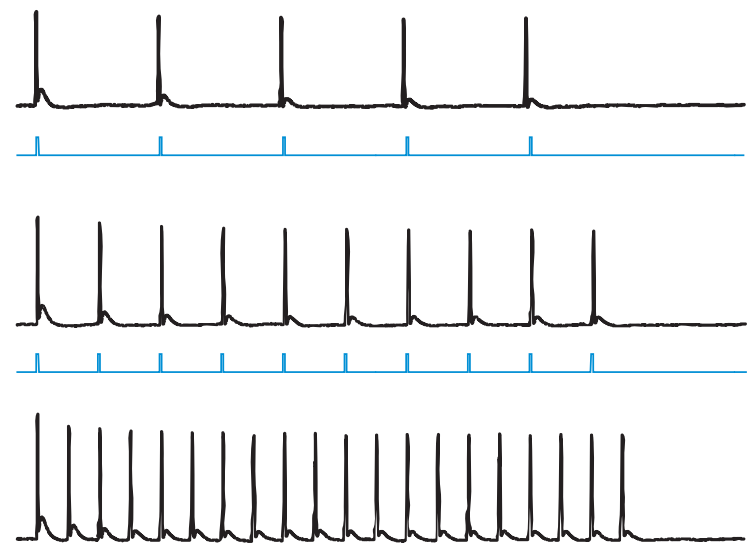

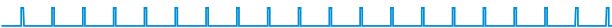
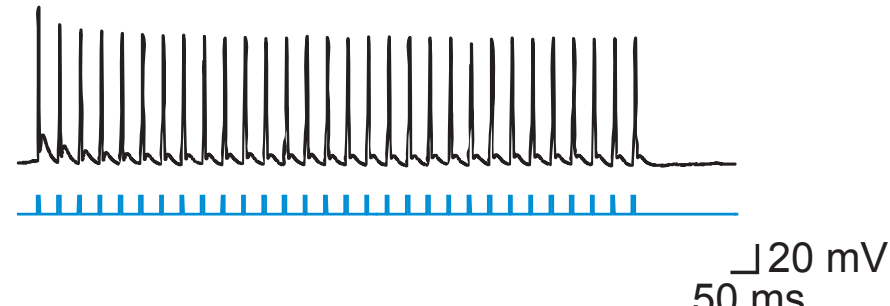

$50 \mathrm{~ms}$
$E$

Electrical

Laser

ChR2-mCherry $20 \mathrm{~Hz} 473 \mathrm{~nm} 10 \mathrm{~s}$

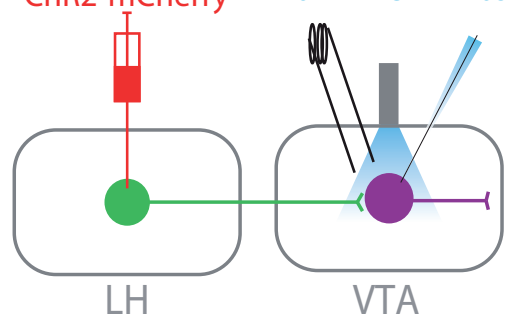

$\mathrm{F}$

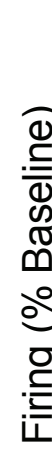

\section{Supplemental Figure 1}


A

E

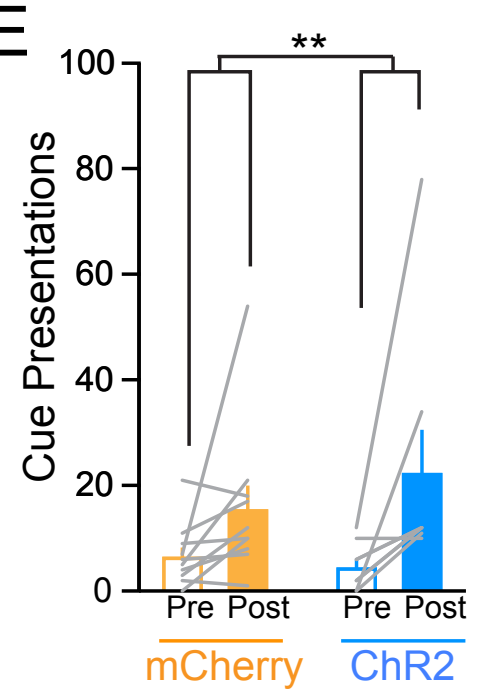

Sucrose Consumption

(PRE)

$60 \mathrm{~m}$

B
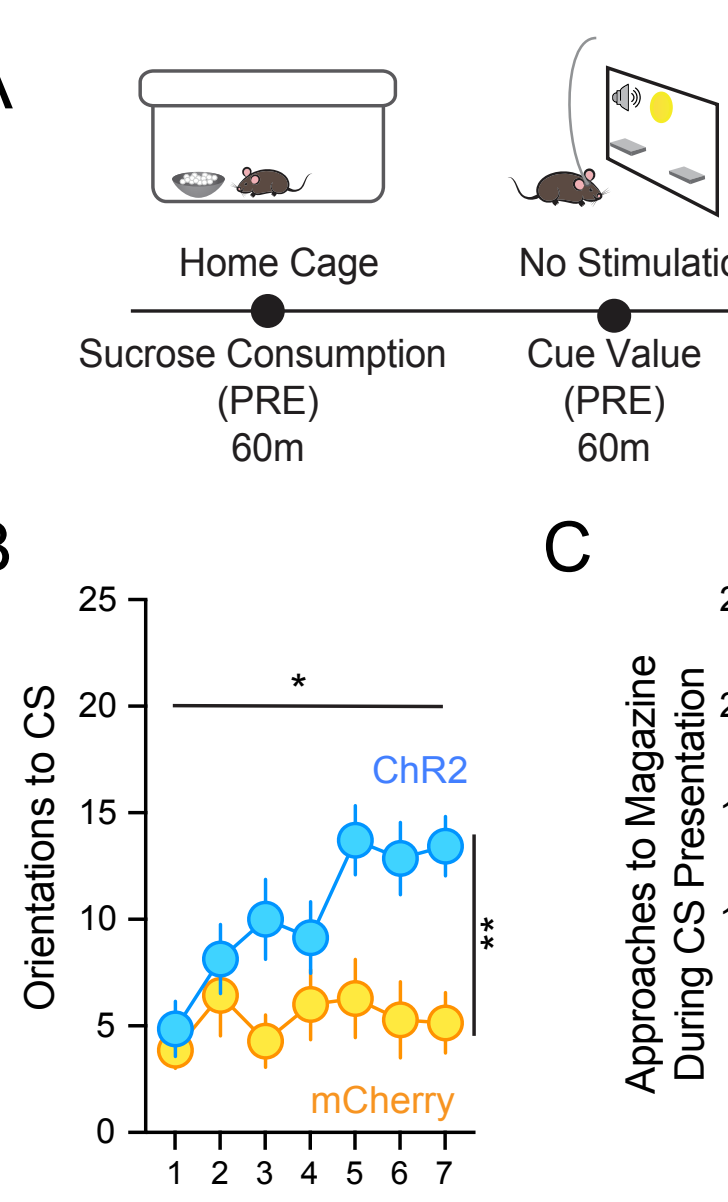

No Stimulation

$20 \mathrm{~Hz}$ Stimulation

C

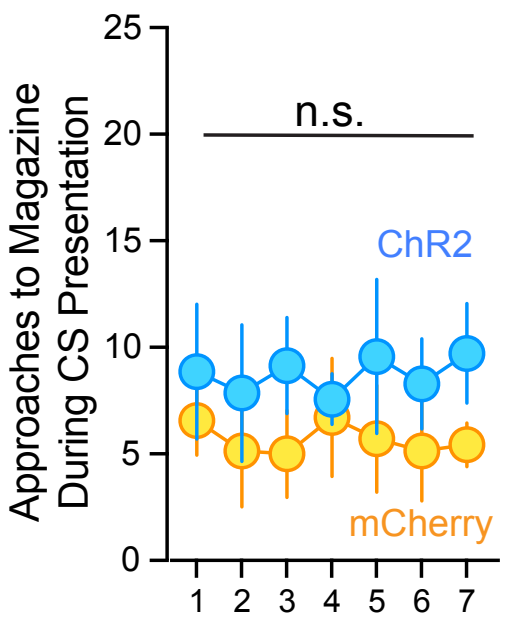

F
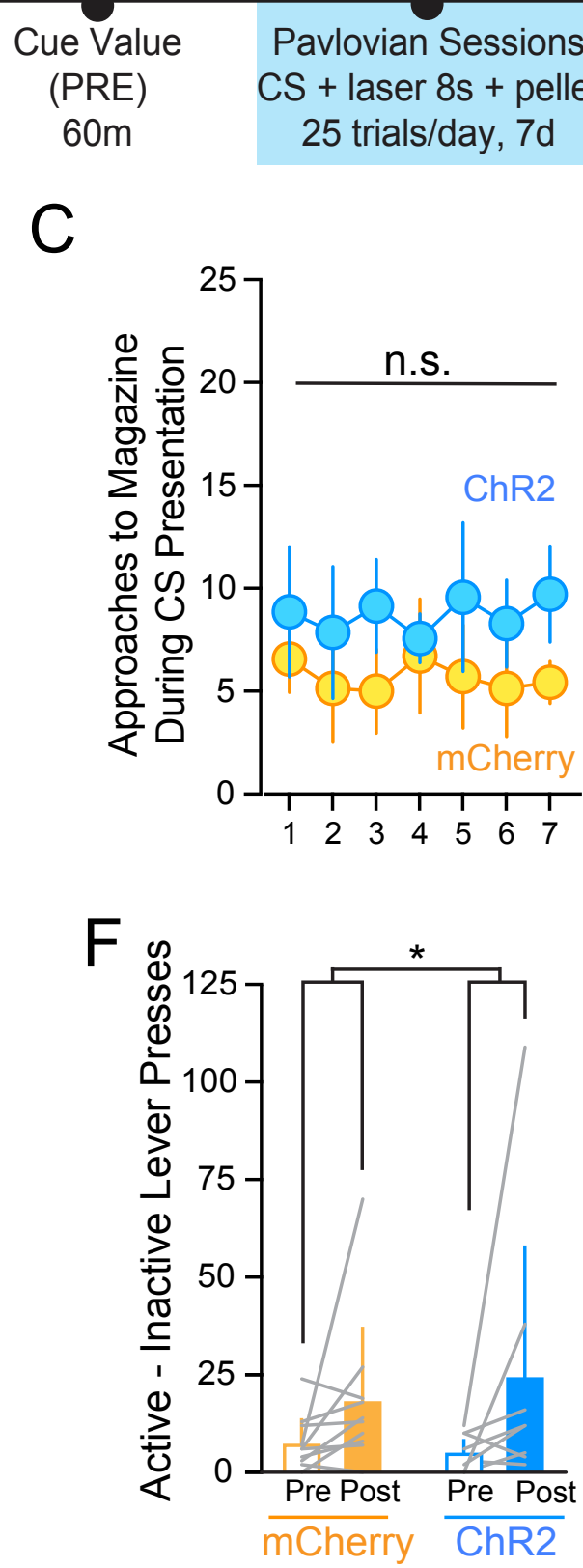

Pavlovian Sessions

25 trials/day, $7 d$
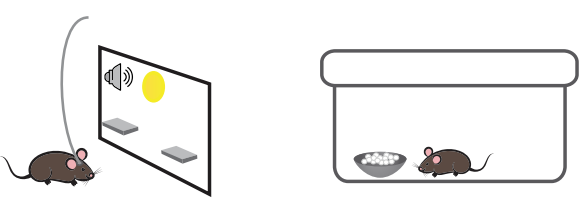

No Stimulation

Home Cage

CS + laser 8s + pellet

Cue Value

(POST)

$60 \mathrm{~m}$

Sucrose Consumption

(POST)

$60 \mathrm{~m}$

D

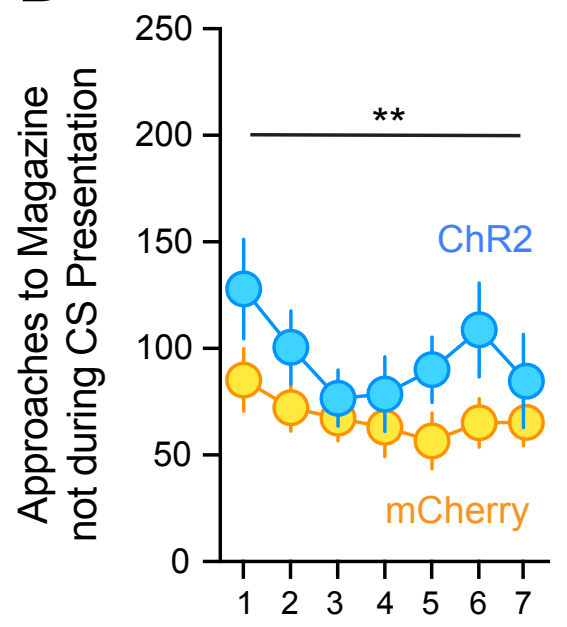

G

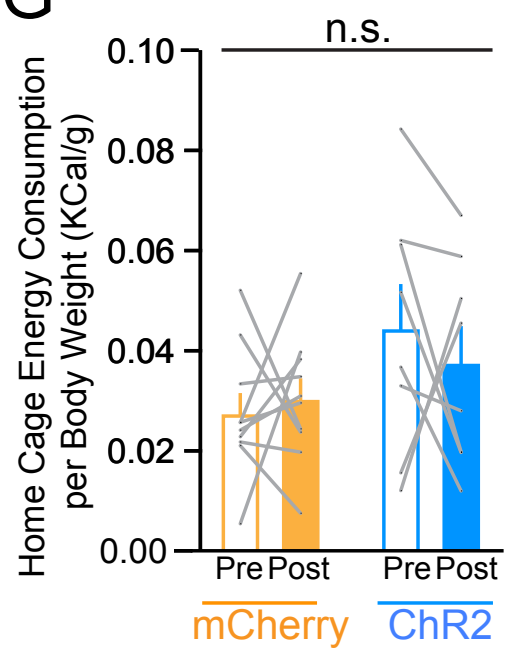

